\title{
OPEN Transcriptomic profiling and pathway analysis of cultured human lung microvascular endothelial cells following ionizing radiation exposure
}

\author{
Roxane M. Bouten ${ }^{1}$, Clifton L. Dalgard ${ }^{2,3}$, Anthony R. Soltis ${ }^{4,5}$, John E. Slaven ${ }^{1}$ \& \\ Regina M. Day $1 \bowtie$
}

The vascular system is sensitive to radiation injury, and vascular damage is believed to play a key role in delayed tissue injury such as pulmonary fibrosis. However, the response of endothelial cells to radiation is not completely understood. We examined the response of primary human lung microvascular endothelial cells (HLMVEC) to $10 \mathrm{~Gy}(1.15 \mathrm{~Gy} / \mathrm{min})$ X-irradiation. HLMVEC underwent senescence (80-85\%) with no significant necrosis or apoptosis. Targeted RT-qPCR showed increased expression of genes CDKN1A and MDM2 (10-120 min). Western blotting showed upregulation of p2/waf1, MDM2, ATM, and Akt phosphorylation (15 min-72 h). Low levels of apoptosis at 24-72 h were identified using nuclear morphology. To identify novel pathway regulation, RNA-seq was performed on mRNA using time points from 2 to $24 \mathrm{~h}$ post-irradiation. Gene ontology and pathway analysis revealed increased cell cycle inhibition, DNA damage response, pro- and anti-apoptosis, and pro-senescence gene expression. Based on published literature on inflammation and endothelialto-mesenchymal transition (EndMT) pathway genes, we identified increased expression of proinflammatory genes and EndMT-associated genes by $24 \mathrm{~h}$. Together our data reveal a time course of integrated gene expression and protein activation leading from early DNA damage response and cell cycle arrest to senescence, pro-inflammatory gene expression, and endothelial-to-mesenchymal transition.

Exposure to thoracic irradiation, accidental or from clinical therapy, can result in Radiation Induced Lung Injury $(\mathrm{RILI})^{1-3}$. Two clinical stages of RILI have been documented in human and animal models ${ }^{2,4,5}$. First, radiation pneumonitis, a pulmonary inflammatory response, develops, usually within $\sim 4-12$ weeks of exposure ${ }^{2,4}$. At about six to twelve months later, pulmonary fibrosis can develop, characterized by fibroblast proliferation, excessive extracellular matrix deposition, and the irreversible loss of normal alveolar architecture ${ }^{2,4,6-10}$. Additionally, radiation can result in pleural effusions in humans and in animal models ${ }^{10}$. Currently, there are no agents approved by the US Food and Drug Administration (FDA) to prevent the development of radiation pneumonitis or the subsequent fibrosis ${ }^{1,11}$.

Changes in the lung vasculature are shown to precede and contribute to RILI, resulting in vascular dysfunction through a variety of mechanisms ${ }^{3,12,13}$. Studies have suggested that microvascular endothelium, which is plentiful in the pulmonary system, is more sensitive to radiation than the endothelium of larger vessels, as the vessel walls of the microvasculature consist only of the layer of endothelial cells (ECs) and a basal lamina ${ }^{14}$. Within a few weeks of irradiation, changes to the endothelium in vivo leads to loss of barrier function, with narrowing and obliteration of capillaries, swelling and hypoplasia in the endothelial layer, and hypoxia in the surrounding

\footnotetext{
${ }^{1}$ Department of Pharmacology and Molecular Therapeutics, Uniformed Services University of the Health Sciences, Bethesda, MD 20814, USA. ${ }^{2}$ The American Genome Center, Uniformed Services University of the Health Sciences, Bethesda, MD 20814, USA. ${ }^{3}$ Department of Anatomy, Physiology and Genetics, Uniformed Services University of the Health Sciences, Bethesda, MD 20814, USA. ${ }^{4}$ Collaborative Health Initiative Research Program, Uniformed Services University of the Health Sciences, Bethesda, MD 20814, USA. ${ }^{5}$ Henry M. Jackson Foundation for the Advancement of Military Medicine, Bethesda, MD 20817, USA. ${ }^{\square}$ email: regina.day@usuhs.edu
} 
tissue ${ }^{9,15,16}$. Blood flow in irradiated tissues is significantly reduced, correlating with reduced microvascular density and diminished oxygen perfusion of the tissues ${ }^{9,16,17}$. In vivo studies demonstrated that radiation microvascular endothelial barrier damage results in increased permeability, fluid extravasation, and lung edema ${ }^{10,15}$.

Chronic inflammation is believed to be a critical contributor to radiation pneumonitis and fibrotic remodeling ${ }^{5,12,18}$. A potential mechanism of increased inflammation is radiation-induced endothelial barrier permeability that allows the extravasation of a variety of inflammatory cells and factors as well as other macromolecules that can contribute to tissue injury. Additionally, the endothelium itself is a key modulator of inflammatory response. Radiation induces increased cytokine secretion in ECs, leading to a pro-inflammatory transcriptional program ${ }^{19}$. Because of the tissue hypoxia and the increased inflammatory response as a result of vascular damage, it has been suggested that mitigating damage to microvascular ECs could provide significant protection for underlying tissues from radiation damage ${ }^{12,20}$.

Investigations into the molecular effects of radiation have been performed to understand the mechanisms underlying the biological damage of radiation to ECs. Radiation initially induces single and double stranded DNA breaks and oxidation of biomolecules from the generation of ROS and RNS (Huang et al., 2017) ${ }^{3,21}$. Apoptosis, DNA damage response, cell cycle alterations, accelerated senescence, and secretory pathway (pro-inflammatory) activation are a few of the signaling pathways demonstrated to be induced in ECs by radiation and the persistent changes in oxidative stress ${ }^{15,22-24}$.

Recently, endothelial-to-mesenchymal transition (EndMT) was shown to precede lung fibrosis in animal models as well as patients with fibrotic lung disease ${ }^{5,25,26}$. EndMT is characterized by the loss of normal EC characteristics, especially loss of cell-cell junctions and increased cell motility ${ }^{26}$. Mesenchymal cell markers including alpha-smooth muscle actin ( $\alpha$-SMA), fibroblast-specific protein-1 (FSP-1), and vimentin are upregulated while standard EC markers, such as platelet endothelial cell adhesion molecule (PECAM-1) and vascular endothelial (VE)-cadherin, are reduced following irradiation ${ }^{5,26,27}$. Inflammatory pathways such as TGF- $\beta$ and TNF- $\alpha$ were also demonstrated to be involved in this process ${ }^{15,26,28,29}$.

The time course of radiation-induced changes in total gene expression is not known in lung microvascular ECs. Here we have addressed this gap of knowledge by examining the change in transcription in cultured human lung microvascular ECs in an early time course following exposure to X-ray irradiation. The RNA-seq time course provides evidence that cascades of gene expression occur in pathways for DNA damage response, cell cycle effects, apoptosis, accelerated senescence, inflammation, and EndMT. Together these findings provide insight into the sequence of cellular events following acute radiation exposure of lung microvascular ECs.

\section{Methods}

Reagents. Chemicals and reagents were purchased from MilliporeSigma (St. Louis, MO, USA) except where indicated.

Cell culture and irradiation. Human lung microvascular endothelial cells (HLMVEC) were purchased from Cell Applications (San Diego, CA, USA), cultured on plates treated with endothelial cell attachment factor in Microvascular Endothelial Cell Growth Medium (Cell Applications) in a humidified environment of 5\% $\mathrm{CO}_{2} / 95 \%$ air at $37^{\circ} \mathrm{C}$, according to the manufacturer's instructions. Cells were used within seven passages for all experiments. Cells were irradiated at 70-90\% confluence using an RS2000 Biological Irradiator (Rad Source Technologies, Alpharetta, GA, USA) at a dose rate of $1.15 \mathrm{~Gy} / \mathrm{min}(160 \mathrm{kV}, 25 \mathrm{~mA})$ for a total dose of $10 \mathrm{~Gy}$ as previously described ${ }^{24,30}$.

Senescence-associated beta-galactosidase (SA- $\beta$-gal) assay and nuclear morphology. Cells were irradiated at $70-90 \%$ confluence and assayed at 24,48 , and $72 \mathrm{~h}$ post-irradiation in triplicate. Dishes were washed twice with phosphate buffered saline (PBS), and fixed with 3.7\% formaldehyde in PBS for 5 min at room temperature, washed twice more with PBS, treated with X-gal solution [1 mg/ml 5-bromo-4-chloro-3indoyl $\beta$-galactopyranoside, $150 \mathrm{mM} \mathrm{NaCl}, 2 \mathrm{mM} \mathrm{MgCl} 2,5 \mathrm{mM} \mathrm{K} 3 \mathrm{Fe}(\mathrm{CN})_{6}, 5 \mathrm{mM} \mathrm{K}{ }_{4} \mathrm{Fe}(\mathrm{CN})_{6}$, citric acid/ sodium phosphate buffer ( $\mathrm{pH} \mathrm{6)}$ ], and incubated at $37^{\circ} \mathrm{C}$ for $20 \mathrm{~h}$ without $\mathrm{CO}_{2}$. Cells were then washed with PBS, treated for 2 min with methanol, and air dried. At least 100 cells were scored in three random fields for expression of $\beta$-galactosidase; all cells in each field were scored. Imaging was performed on an Olympus IX73 fluorescence microscope (Olympus, Center Valley, PA) using $\times 10$ magnification at $488 \mathrm{~nm}$ or using phase contrast. For nuclear morphology analysis, cells were grown on coverslips and irradiated at $70-90 \%$ confluence. At the required time points, cells were washed with PBS and fixed for $5 \mathrm{~min}$ in buffered formalin at room temp. Cells were then washed again with PBS, and then mounted on slides in Prolong Gold antifade reagent with DAPI (Invitrogen, Eugene, OR, USA). Cells were imaged as for SA- $\beta$-gal. All nuclei were analyzed in 5 random images, to allow counting of at least 100 nuclei per slide, with three slides per time point.

Lactate dehydrogenase assay. HLMVEC were grown to 70-90\% confluence and 5000-6000 cells per sample were irradiated or sham-irradiated, and assayed using the Invitrogen CyQUANT LDH Cytotoxicity Assay Kit (Thermo Fisher Scientific, Eugene, OR, USA) according to the manufacturer's product information sheet. Plates were read using a Cytation 5 imaging plate reader (BioTek, Winooski, VT, USA). Assays were performed in triplicate.

Quantitative PCR analysis. HLMVEC were irradiated at 70-90\% confluence, and total RNA was isolated from HLMVEC using the RNeasy Mini Kit with on-column DNase digestion (Qiagen, Valencia, CA, USA) according to manufacturer's protocol. RNA was quantified spectroscopically (ND-1000 Spectrophotometer, Nano-Drop, Wilmington, DE, USA) and $1.0 \mu \mathrm{g}$ was reverse transcribed using iScript cDNA synthesis kit (Bio- 


\begin{tabular}{|c|c|c|}
\hline HGNC gene symbol & Forward Primer & Reverse Primer \\
\hline ACTA2 & 5'-TATCCCCGGGACTAAGACGGG-3' & 5'-CAGAGCCCAGAGCCATTGTC-3' \\
\hline ATM & 5'-AGTGGGACCATTGCACTTCC-3' & 5'-CAAGGCTGCGCTTACACATC-3' \\
\hline BBC3 & 5'-GACGACCTCAACGCACAGTA-3' & 5'-TAATTGGGCTCCATCTCGGG-3' \\
\hline BCL2A1 & 5'-AAATTGCCCCGGATGTGGATA-3' & 5'-TGGGCCACTGACTCTACCAG-3' \\
\hline CCL2 & 5'-GATCTCAGTGCAGAGGCTCG-3' & 5'-TTTGCTTGTCCAGGTGGTCC-3' \\
\hline CCND2 & 5'-GTGCTGGGGAAGTTGAAGTG-3' & 5'-GATCATCGACGGTGGGTACA-3' \\
\hline CDKN1A & 5'-ACTCTCAGGGTCGAAAACGG-3' & 5'-GATGTAGAGCGGGCCTTTGA-3' \\
\hline CDKN2B & 5'-CAACGGAGTCAACCGTTTCG-3' & 5'-ACATCGGCGATCTAGGTTCC-3' \\
\hline E2F1 & 5'-CCGGGGAATGAAGGTGAACA-3' & 5'-GAGCAAAAGGGCCGAAAGTG-3' \\
\hline ESPL1 & 5'-TCCTGCTGCTACGGATTGTC-3' & 5'-CGAGATGCTTCAGGCTCGAT-3' \\
\hline FAS & 5'-CTGTGACCCTTGCACCAAATG-3' & 5'-GACAAAGCCACCCCAAGTTAG-3' \\
\hline FLT1 & 5'-TCACTCAGCGCATGGCAATA-3' & 5'-CTCTCCTTCCGTCGGCATTT-3' \\
\hline GAPDH & 5'-AGCCACATCGCTCAGACAC-3' & 5'-GCCCAATACGACCAAATCC-3' \\
\hline HEY1 & 5'-GGCTCTAGGTTCCATGTCCC-3' & 5'-CCTTGCTCCATTACCTGCTTC-3' \\
\hline HIPK2 & 5'-TCCCCGTTGCCATGAACC-3' & 5'-ACCCAGTCATGTCCCAGTTG-3' \\
\hline ICAM1 & 5'-ACCCCGTTGCCTAAAAAGGA-3' & 5'-GGGTAAGGTTCTTGCCCACT-3' \\
\hline IGF1R & 5'-CCGATGTGTGAGAAGACCAC-3' & 5'-GTGGCAGCACTCATTGTTCT-3' \\
\hline IGFBP3 & 5'-TGCTAGTGAGTCGGAGGAAGA-3' & 5'-CAACTTTGTAGCGCTGGCTG -3' \\
\hline IL1A & 5'-GGGAGTCATTTCATTGGCGT-3' & 5'-TGGAGTGGGCCATAGCTTACA-3' \\
\hline LIF & 5'-CCTCTGAAGTGCAGCCCATA-3' & 5'-GTTGTGACATGGGTGGCGTA-3' \\
\hline MDM2 & 5'-TGGTGAACGACAAAGAAAACG-3' & 5'-GTAACTTGATATACACCAGCATCAA-3' \\
\hline MTOR & 5'-CAAATGTGTGCAGTTCCTGCC-3' & 5'-CAAAGGACACCAACATTCCCA-3' \\
\hline ORC1 & 5'-CATACCCTCACGAAGGTGCC-3' & 5'-CAGCAGAAACATGCAGCCTC-3' \\
\hline PIK3CA & 5'-GAGGTTTGGCCTGCTTTTGG-3' & 5'-GGTCGCCTCATTTGCTCAAC-3' \\
\hline PIK3CB & 5'-GATGCCCTTCTGAACTGGCT-3' & 5'-GTCAATGTGGAAGAGCTGGC-3' \\
\hline PIK3CD & 5'-CTTCCTCCACCTCTTTGCCC-3' & 5'-TCCTCTGTTTTCCCCAGTGC-3' \\
\hline PIK3CG & 5'-TGATCTGCGCCAAGACATGC-3' & 5'-ATTGTCGTGGCGTCTTTCAC-3' \\
\hline RAD9A & 5'-AGCCCTTTTCCCAGAGTTACA-3' & 5'-GCAGCATTTTTCCACCGTCTT-3' \\
\hline RASSF5 & 5'-TAAGCGGATACACAAGGACGG-3' & 5'-GTTCAGGGATGGAGAAGGCAT-3' \\
\hline RPS6KB1 & 5'-GATTTATTGGCAGCCCACG-3' & 5'-GCTTCСССАCTCATTGTCAC-3' \\
\hline SESN1 & 5'-GGCGTACACGGCCCCTTT-3' & 5'-GGATGAATCTGCTTGGTCCCT-3' \\
\hline SIRT1 & 5'-GCAGATTAGTAGGCGGCTTG-3' & 5'-TCTGGCATGTCCCACTATCAC-3' \\
\hline TP53 & 5'-GACACGCTTCCCTGGATTG-3' & 5'-TCAGGAAGTAGTTTCCATAGGT-3' \\
\hline TRAF1 & 5'-CCTTGAGGTCACCCAGACAC-3' & 5'-CTGGCTTGTGTGGTTCAACG-3' \\
\hline TUBULIN & 5'-СТССАТССТСАСССАСАС-3' & 5'-CAGGGTCACATTTCACCATCT-3' \\
\hline VIM & 5'-GGACCAGCTAACCAACGACA-3' & 5'-AAGGTCAAGACGTGCCAGAG-3' \\
\hline
\end{tabular}

Table 1. Primers for qPCR.

Rad, Hercules, CA, USA), according to the manufacturer's protocol. Complementary DNA (cDNA) was diluted tenfold with nuclease-free water and $2 \mu \mathrm{l}$ was used in each $20 \mu \mathrm{l}$ RT-qPCR reaction. RT-qPCRs were performed with technical triplicates using $6 \mu \mathrm{M}$ of each primer and $10 \mu \mathrm{l}$ of $\mathrm{iTaq}^{\text {Tn }}$ Universal SYBR Green Supermix (Bio$\mathrm{Rad}$ ), on a CFX96 Touch Real-Time PCR Detection System (Bio-Rad). Primers for qRT-PCR were designed using NCBI /Primer-BLAST and purchased from Integrated DNA Technologies (Coralville, IA, USA). Forward and reverse primer sequences are shown in Table 1 . Relative gene expression to the reference genes was calculated using the $\Delta \Delta \mathrm{Cq}$ method using CFX Maestro software, 2.0 (Bio-Rad) ${ }^{31,32}$.

Western blotting. HLMVEC were irradiated at 70-90\% confluence. Cells were lysed in RIPA buffer (1\% NP-40, 0.1\% SDS, 0.1\% Na-deoxycholate, $10 \%$ glycerol, $0.137 \mathrm{M} \mathrm{NaCl}, 20 \mathrm{mM}$ Tris pH [8.0]) (Thermo Fisher Scientific), protease (\#A32953, Thermo Fisher) and phosphatase (\#A32957, Thermo Fisher Scientific) inhibitor cocktails for $20 \mathrm{~min}$ at $4{ }^{\circ} \mathrm{C}$, vortexed, rotated at $4{ }^{\circ} \mathrm{C}$ for $20 \mathrm{~min}$, then centrifuged at $15,000 \times g$ for $15 \mathrm{~min}$. Protein concentrations were determined using the BCA protein assay (MilliporeSigma). Clarified lysates were boiled in SDS sample buffer containing $100 \mathrm{mM}$ DTT for $5 \mathrm{~min}$ prior to resolution by sodium dodecyl sulfate-polyacrylamide gel electrophoresis (Criterion TGX precast, Bio-Rad). Proteins were transferred to nitrocellulose membranes (MilliporeSigma). Proteins were identified using primary antibodies: anti-p53 (Santa Cruz Biotechnology [Santa Cruz, CA, USA] \#sc-256; 1:1000; or Cell Signaling [Danvers, MA, USA] \#2527; 1:1000), anti-insulin-like growth factor 1 receptor (IGF1R; Cell Signaling \#3027; 1:500), anti-phospho-IGF1R Tyr980 (Cell Signaling \#4568; $1: 500$ ), anti- $\beta$-actin (Sigma \#AC-15; 1:5,000), anti-mouse double minute 2 homolog (MDM2; Cell Signaling \#86934; 1:1000), anti-ataxia telangiectasia mutated (ATM, Cell Signaling \#4267; 1:1000), 
anti-phospho-ATM Ser1981 (Cell Signaling 13050; 1:1000), anti-p21 (waf1) (Cell Signaling \#2947; 1:1000), anti-phospho-AKT Ser473 (Cell Signaling 4060; 1:1000), anti-AKT (Cell Signaling \#2920; 1:1000), and anticleaved caspase 3 (Cell Signaling \#9661; 1:500). Anti-mouse and anti-rabbit secondary antibodies conjugated to IRDye680 or IRDye800 (LI-COR, Lincoln, NE, USA; 1:10,000) were used to probe primary antibodies. Western blot protein bands were detected and quantified using the Odyssey system (LI-COR). For quantification, samples were normalized to $\beta$-actin.

Transcriptome profiling by RNA sequencing. HLMVEC were irradiated at $70-90 \%$ confluence. Total RNA was isolated from cells using the RNeasy Mini Kit with on-column DNase digestion (Qiagen) according to manufacturer's protocol. RNA was quantified spectroscopically (ND-1000 Spectrophotometer, Nano-Drop, Wilmington, DE, USA). The total RNA integrity was assessed using automated capillary electrophoresis with a Fragment Analyzer (Roche, Pleasanton, CA, USA). For all samples with an RNA quality indicator (RQI) $>8.0$, a total of $>75 \mathrm{ng}$ RNA was used as the input for library preparation using the TruSeq Stranded mRNA Library Preparation Kit (Illumina, San Diego, CA, USA). The sequencing libraries were quantified by Real-Time PCR on a Roche LightCycler 480 Instrument II using a KAPA Library Quantification Kit for NGS (Kapa, Wilmington, MA, USA). The size distribution was assessed by automated capillary-based gel electrophoresis with a Fragment Analyzer to confirm absence of free adapters or adapter dimers. The sequencing libraries were pooled and sequenced on a NovaSeq 6000 Sequencer (Illumina) using a NovaSeq 6000 SP Reagent Kit (300 cycles) within one flowcell lane using an XP workflow with $101+8+8+101$ cycle parameters with paired-end reads of $75 \mathrm{bp}$ in length. Raw sequencing reads were demuxed using bcl2fastq2 (v2.20) and aligned to the human reference genome (hg38) with MapSplice (v2.2.2) ${ }^{33}$. Gene-level quantification was performed with HTSeq (v0.9.1) ${ }^{34}$ against GENCODE (v28) basic gene annotations. Read alignment statistics and sample quality features were calculated with Samtools and $\mathrm{RSeQC}^{35-37}$. Sequencing quality was verified by manual inspection of sample-wise characteristics: total reads, mapping percentages, pairing percentages, transcript integrity number (TIN), $5^{\prime}$ to $3^{\prime}$ gene body read coverage slopes, and ribosomal RNA content ${ }^{38}$. The transcript abundance quantitation data were deposited in the NCBI Gene Expression Omnibus (GSE179810). Time-series differential expression analysis was performed with DESeq2 (v1.16.1) ${ }^{39}$ on raw gene counts using a likelihood-ratio test (LRT) framework, whereby a full model including stimulation time information was compared against a reduced model including only an intercept term. We defined significant time series differentially expressed genes (DEGs) as those with an LRT False Discovery Rate (FDR) q-value $<0.05$, an absolute fold change $>1.5$ (i.e. $\mid \log 2$ (fold-change) $\mid>0.585$ ) at one or more time points compared to controls, and mean transcripts per million (TPM) $\geq 1$ across samples.

Gene ontology, pathway enrichment analysis, and heat map construction. Gene Ontology (GO) and Kyoto Encyclopedia of Genes and Genomes (KEGG) pathway analyses were performed using the Database for Annotation, Visualization, Integrated Discovery (DAVID), version 6.8. with the medium classification stringency, an enrichment threshold of 0.05 , and the Bonferroni method of adjustment for multiple testing (Laboratory of Human Retrovirology and Immunoinformatics, Frederick, MD, USA ${ }^{40}$; https://david.ncifcrf. gov $/)^{41}$, g:Profiler (https://biit.cs.ut.ee/gprofiler/) ${ }^{42}$; and Gene Ontology enRIchment anaLysis and visuaLizAtion tool (GOrilla), version 4.1 (http://cbl-gorilla.cs.technion. ac.il/ $)^{43,44}$. Heatmaps were generated using ClustVis software (https://biit.cs.ut.ee/clustvis/) ${ }^{45}$. Venn diagrams were constructed using Venny, version 2.1 (Juan Carlos Oliveros, BioInfoGP Service, Centro Nacional de Biotecnologia, Madrid, Spain; https://bioinfogp.cnb.csic.es/ tools/venny/). The summary figure for pathway interconnections was generated using Metascape (https://metas cape.org $\left.{ }^{46}\right)$.

Statistics. Statistical analyses of assays were performed using Graphpad Prism 7 (San Diego, CA, USA) or Excel. For RNA-seq and qPCR analysis, one way ANOVA with a post-test analysis was used for comparing multiple data sets. For western blot analysis, two-way ANOVA with either Tukey's or Sidak's post-hoc tests for multiple comparisons.

\section{Results}

Accelerated senescence observed in endothelial cells after $10 \mathrm{~Gy}$ X-irradiation. We previously reported that the primary response of human pulmonary artery endothelial cells (HPAEC) to 10 Gy X-irradiation was accelerated senescence ${ }^{24,30}$. However, it was postulated that ECs from large vessels have different responses to radiation compared with microvascular $\mathrm{ECs}^{14}$. Therefore, we investigated the effects of radiation on human lung microvascular endothelial cells (HLMVEC) exposed to $10 \mathrm{~Gy} \mathrm{X}$-irradiation. Accelerated senescence, necrosis, and apoptosis were measured. Senescence was significantly increased 24-72 h (Fig. 1a-f). Senescent cells displayed characteristic "fried egg" morphology with expression of senescence-associated beta galactosidase (Fig. 1a,b). Cells did not display significant necrosis, as indicated by lactate dehydrogenase release in the medium in response to radiation from 24,48 , and $72 \mathrm{~h}$ (Fig. 1c). We were unable to detect significant apoptosis using western blotting for cleaved caspase-3 (Fig. 1d). We next performed nuclear morphology analysis to detect low levels of apoptosis occurring over the time course (Fig. 1e,f). Nuclear blebbing is consistent with late apoptotic events. We observed a trend toward 3.6-11.9\% apoptosis at $24-72 \mathrm{~h}$ post-irradiation, respectively, although these levels did not reach significance due to variation between experiments (Fig. 1f).

Our laboratory and others demonstrated the regulation of a variety of signaling pathways in vitro response to radiation, including pathways regulating growth regulation, DNA repair, and cell death ${ }^{24,30,47}$. We investigated alterations in HLMVEC mRNA changes in an early time course (10-120 min) following 10 Gy X-ray irradiation exposure (Fig. 2). The most rapid change was in IGF1R mRNA, which increased significantly at all time points tested with maximum expression $(\sim 5-6.5$-fold, $p<0.05)$ from $10 \mathrm{~min}$ through $2 \mathrm{~h}$ post-irradiation. 
a

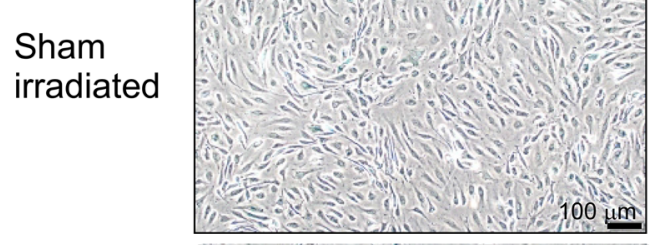

10 Gy X-ray, 3 days

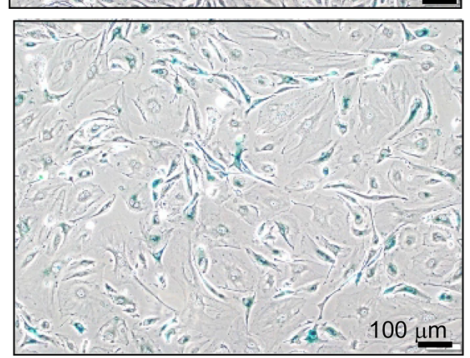

C

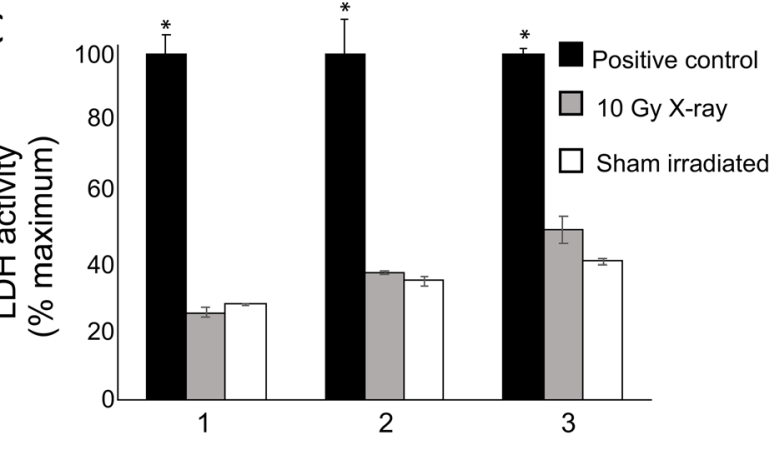

Time post-irradiation (days)

e

Sham

irradiated
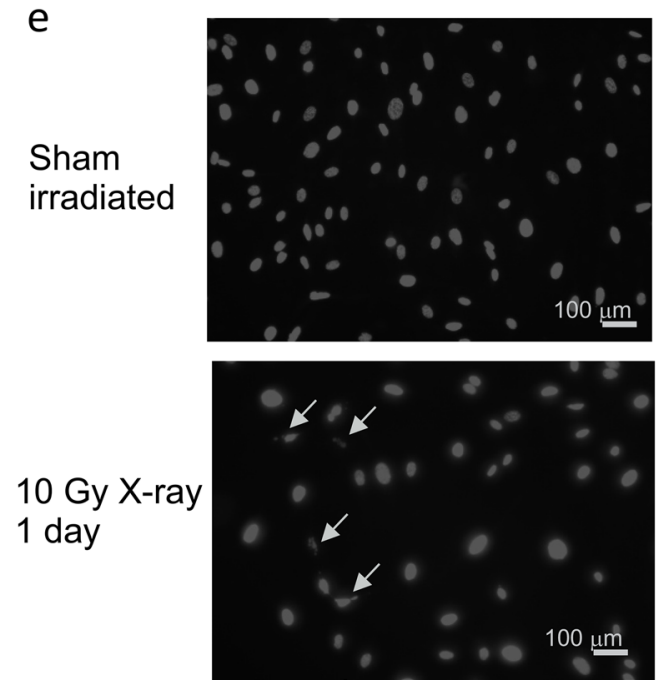

b $\square 10$ Gy X-ray

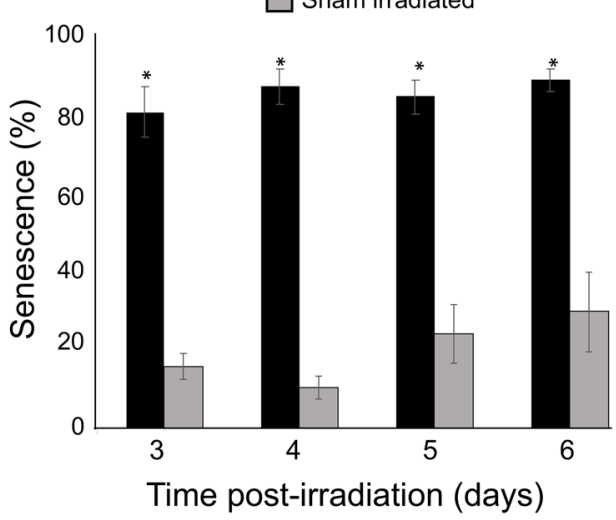

d

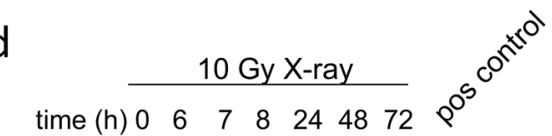

cleaved

caspase-3

$19 \mathrm{kDa}$

$17 \mathrm{kDa}$

$\beta$-actin $\Rightarrow=-1-2 \times d$

$42 \mathrm{kDa}$

f

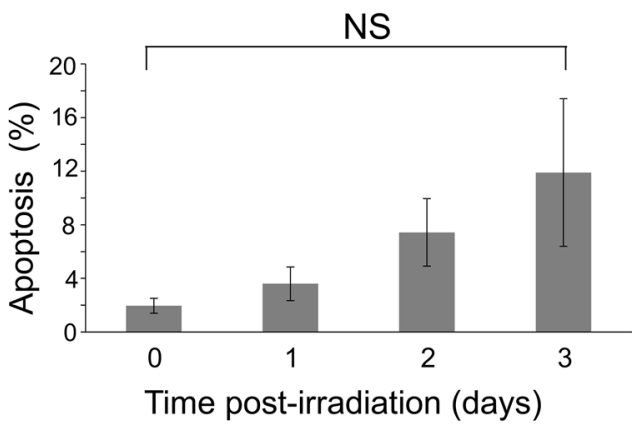

Figure 1. $10 \mathrm{~Gy} \mathrm{X}$-irradiation induces accelerated senescence, but not necrosis or apoptosis in HMLVEC. HLMVEC were grown to $70 \%$ confluence and sham irradiated or X-irradiated at $10 \mathrm{~Gy}$. (a) Cells were stained for SA- $\beta$-gal activity at indicated times post-irradiation, and scored for SA- $\beta$-gal staining and senescent morphology. Representative images of SA- $\beta$-gal staining and cell morphology in control and irradiated HMLVEC. (b) All cells were counted in three random fields per dish (minimum 100 cells per field). The graph indicates means \pm SE $n=6$; ${ }^{*} p<0.05$ from sham irradiated. (c) LDH released into the medium was measured at 24,48 , and $72 \mathrm{~h}$ post-irradiation. Cell death by necrosis is expressed as a percentage of $\mathrm{LDH}$ in the medium of irradiated or sham irradiated cells divided by the $\mathrm{LDH}$ released in medium of positive control treated cells. Bars indicate mean \pm standard error, $n=3 .{ }^{*} p<0.05$ from sham irradiated. (d) HLMVEC were grown to $70 \%$ confluence and X-irradiated at $10 \mathrm{~Gy}$. Cell lysates were prepared at the indicated time points, and western blots were performed for cleaved caspase 3 as an indication of apoptotic signaling. A positive control is provided for cleaved caspase 3 (pos control). (e) Cells stained with DAPI to visualize nuclear morphology to identify apoptotic nuclei. (f) Nuclei were scored from random fields to determine percentage of apoptotic nuclei; graph shows average of percent apoptosis \pm SEM; NS = not significant. 

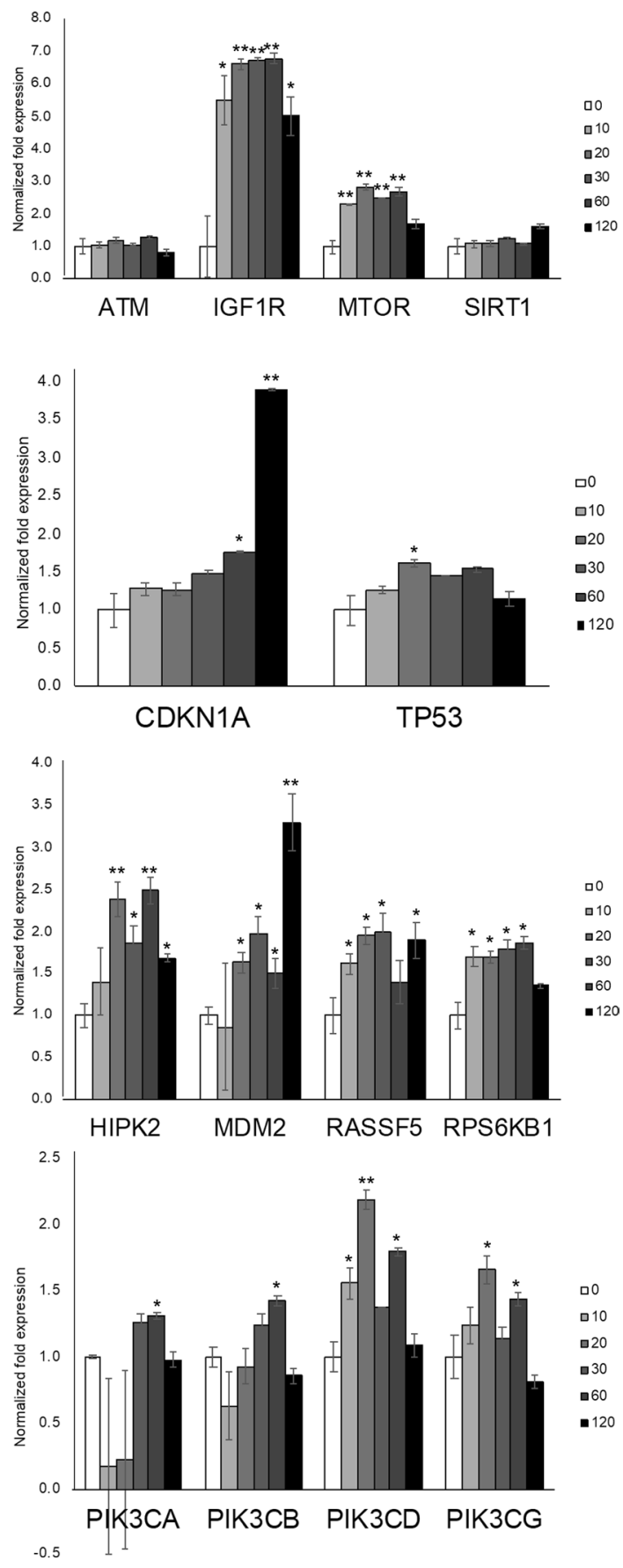

Figure 2. Gene expression changes in irradiated HLMVEC. HLMVEC were grown to $70 \%$ confluence and exposed to $10 \mathrm{~Gy}$ X-ray irradiation. RNA was obtained at the indicated time points. mRNA levels in irradiated HLMVEC were assessed by RT-qPCR at indicated time points post-irradiation. Graph represents means, \pm SEM from $\mathrm{n}=3$ independent experiments. $p<0.05$ is indicated by ${ }^{*}, p<0.01$ is indicated by ${ }^{* *}$.

Cyclin dependent kinase inhibitor 1A (CDKN1A) increased by fourfold, and murine double minute 2 (MDM2), an E3 ubiquitin ligase regulator of $\mathrm{p} 53$, increased $\sim$ threefold, both at $2 \mathrm{~h}$ (both $p<0.05$ ). Phosphatidylinositol 3-kinase $(P I 3 K)$ proteins integrate cell growth in response to stress. The PIK3CD isoform of PI3K was increased at $20 \mathrm{~min}$ post-irradiation $(p<0.05)$. We also observed trends toward increased expression in several stress response and survival genes: homeodomain interacting protein kinase-2 (HIPK2), mammalian target of rapamycin (MTOR), Ras association domain family member (RASSF5), and ribosomal protein S6 kinase B1 $(R P S 6 K B 1)^{48,49}$. Interestingly, we observed no significant changes gene expression for genes encoding proteins associated with DNA repair, stress response, or cell growth regulation: the DNA damage response serine/threonine kinase ataxia-telangiectasia mutated (ATM) gene; the transcription factor tumor protein p53 (TP53), which 
regulates senescence-associated genes; and sirtuin 1 (SIRT1), which is activated by oxidative stress and DNA damage to regulate survival.

Western blotting was performed to examine the regulation of selected proteins by radiation in a time course from 15 min through $72 \mathrm{~h}$ (Fig. 3). Consistent with the RT-qPCR findings, we observed an upregulation of p21/ wafl, (gene CDKN1A) and MDM2 within $2 \mathrm{~h}$ post-irradiation that was sustained through $72 \mathrm{~h}$. Phosphorylated Akt, often a surrogate of PI3K activation, was increased at $2 \mathrm{~h}$ post-irradiation, consistent with the time point for upregulation of PI3KCD mRNA. Total and phosphorylated ATM were increased within 15 min, consistent with the role of ATM in DNA damage response. Increase in phosphorylated ATM was sustained through $4 \mathrm{~h}$, but the increase in total ATM was maintained through $72 \mathrm{~h}$. The level of p53 and IGF1R displayed trends of reduced levels at early time points, that returned to basal levels $\sim 2 \mathrm{~h}$ post-irradiation. We unable to observe significant increases in IGF1R phosphorylation, but this may be because cells were not synchronized prior to irradiation.

Genome-wide transcriptional responses to $10 \mathrm{~Gy}$ X-irradiation. Targeted gene expression analysis provides information regarding known genes with predicted functions in biological processes. To discover previously unidentified gene regulation, and to expand known pathways in primary HLMVEC in response to ionizing radiation, we used comprehensive transcriptome profiling by RNA sequencing (RNA-seq). Gene expression profiles from sham-irradiated (control) HLMVEC were compared with irradiated HLMVEC at 2, 4, 6, 8, and $24 \mathrm{~h}$. Comparative differential expression analysis identified differential gene expression of 9,151 transcripts over all time points, with a q-value $<0.05$ (Supplemental Table S1). In order to interpret the functional relationship of candidate DEG in response to ionizing radiation, we filtered for coding transcripts that were differentially expressed in excess of 1.5-fold as compared to the control group. Based on these criteria, we observed 3,581 unique significant DEGs in the irradiated cells irradiated vs the control cells, irrespective of time point (Supplemental Table S1).

The differences in gene expression patterns post-irradiation compared to controls were very robust at 2, 8 and $24 \mathrm{~h}$, indicating significant gene expression activity at these time points (Fig. 4a). Because of this we focused on these three time points for our initial analysis to gain an overall picture of changes in gene expression, and later considered all of the time points in targeted biological pathway analysis. Two Venn diagrams of the data from 2, 8 and $24 \mathrm{~h}$ illustrate the overlap of the differentially expressed genes up- and down-regulated in response to $10 \mathrm{~Gy}$ irradiation (Fig. 4b). At 2 and $8 \mathrm{~h}$ post-irradiation, downregulated genes outnumbered upregulated genes, with 442 and 732 genes downregulated at 2 and $8 \mathrm{~h}$ respectively and 322 and 521 upregulated, respectively. At $24 \mathrm{~h}$ post-irradiation the number of DEGs upregulated vs downregulated were reversed with 1,651 genes upregulated and 1,271 genes downregulated. mRNA expression levels of selected genes were analyzed using real-time qPCR. We selected genes (ACTA2, BBC3, BCL2A1, CCNE2, E2F1, ESPL1, FAS, IGFBP3, ORC1, SESMN1, and VIM) that were highly regulated in our sequencing data and represented in the six biological pathways we identified as affected by $10 \mathrm{~Gy} \mathrm{X}$-irradiation (cell cycle, apoptosis, DNA damage, inflammatory response, senescence, and EndMT). The results from RT-PCR correlated well in the direction of regulation with the sequencing-derived mRNA expression levels. Overall, the RNA-seq results were in good agreement with the qPCR, although there were a few instances in which the results diverged (Supplemental Fig. S1). The $2 \mathrm{~h}$ time point provided most of the differences, with expression measured using qPCR higher than RNA-seq. In many of these cases, the qPCR expression is also more variable than the RNA-seq results. The other three times points do not show significant differences suggesting the issue was in the samples or execution of the qPCR at one time point.

Gene ontology and pathway analysis post-irradiation. To identify enrichment of pertinent gene ontology (GO) term clusters, we analyzed 2, 8 and 24 h gene sets using DAVID (v 6.8 $)^{40,41}$. Analyses were focused on GO terms and KEGG pathways relevant to cellular response pathways and to the endothelium. The biological processes (BP) graphs show clusters with enrichment scores greater than 1.6 and the $y$-axis is labeled with the term having the highest fold enrichment in that cluster (Fig. 5). For the KEGG pathway graphs we included all of the relevant to cell biology; these pathways were visualized using DAVID (Supplementary Figs. S2-S4). GOrilla $(\mathrm{v} 4.1)^{43,44}$ was used to identify biological processes enriched $\left(p \leq 10^{-5}\right)$ in our data, with a focus on categories relevant to cell biology with cluster enrichment scores greater than 1.6, labeling the graph with terms having the highest fold enrichment in the cluster. The pathways with the most enrichment for downregulated pathways are shown in Fig. S5, and the pathways with the most enrichment for upregulation are shown in Fig. S6. DAVID analysis showed that at $2 \mathrm{~h}$ post-irradiation, the largest changes (both up- and down-regulation) in BP terms were cell cycle, apoptosis, and DNA damage terms, as well as the related terms, cell proliferation and transcription regulation (Fig. 5a). Consistent with these, we observed enriched KEGG pathways for p53, TGF- $\beta$, and TNF signaling, as well as cell cycle at $2 \mathrm{~h}$ (Fig. 5b). These pathways, as well as FoxO, and Hippo, suggested the regulation of genes associated with cellular senescence and apoptosis. GO terms related to hypoxia, cell migration, and mesenchymal cell development were also increased. Remarkably, analysis of down-regulated GO term clusters enriched showed that all major down-regulations at $2 \mathrm{~h}$ and the majority of the clusters at 8 and $24 \mathrm{~h}$ involve cell cycle terms (Supplementary Figs. S5). The GOrilla GO term analysis agreed with the DAVID GO clustering and KEGG pathway analysis, with the most enriched terms associated with cell cycle events (spindle checkpoint, sister chromatid segregation, and metaphase/anaphase transition) and signal transduction by p53 class mediator, and transcription regulation. GOrilla analysis also revealed enrichment in terms related to the TGF- $\beta$ signaling pathway, positive regulation of cell migration, and response to hypoxia.

At $8 \mathrm{~h}$ post-irradiation, DAVID analyses showed that the most enriched BP cluster was response to hypoxia, followed by terms related to regulation of proliferation, motility, and migration, suggesting a continuation of the response seen at $2 \mathrm{~h}$ post-irradiation (Fig. 5c). Clusters of gene regulation terms for apoptosis, cell cycle, and DNA damage were present but to a lesser degree. At $8 \mathrm{~h}$, the most enriched KEGG pathway was p53 signaling 


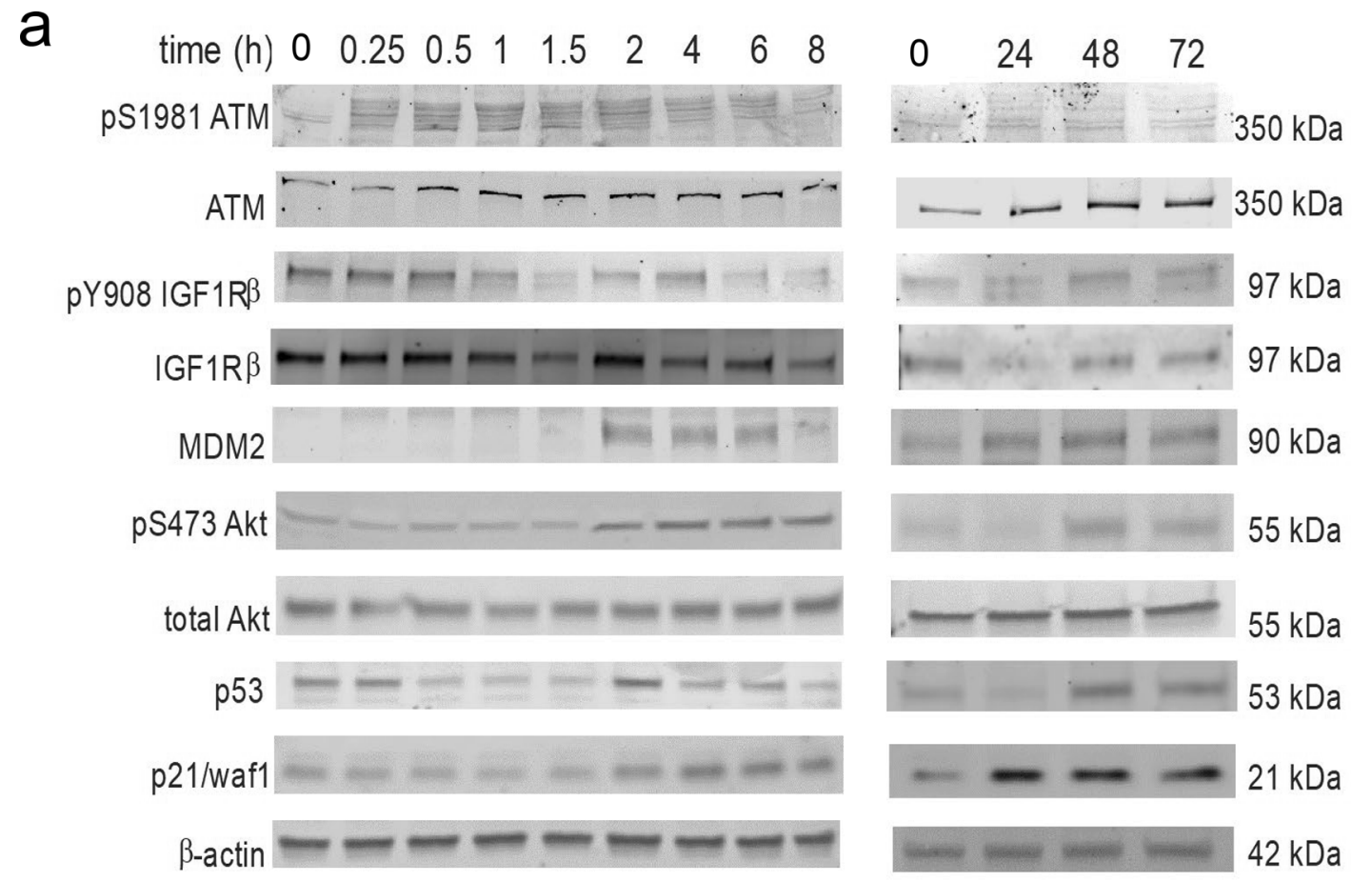

b
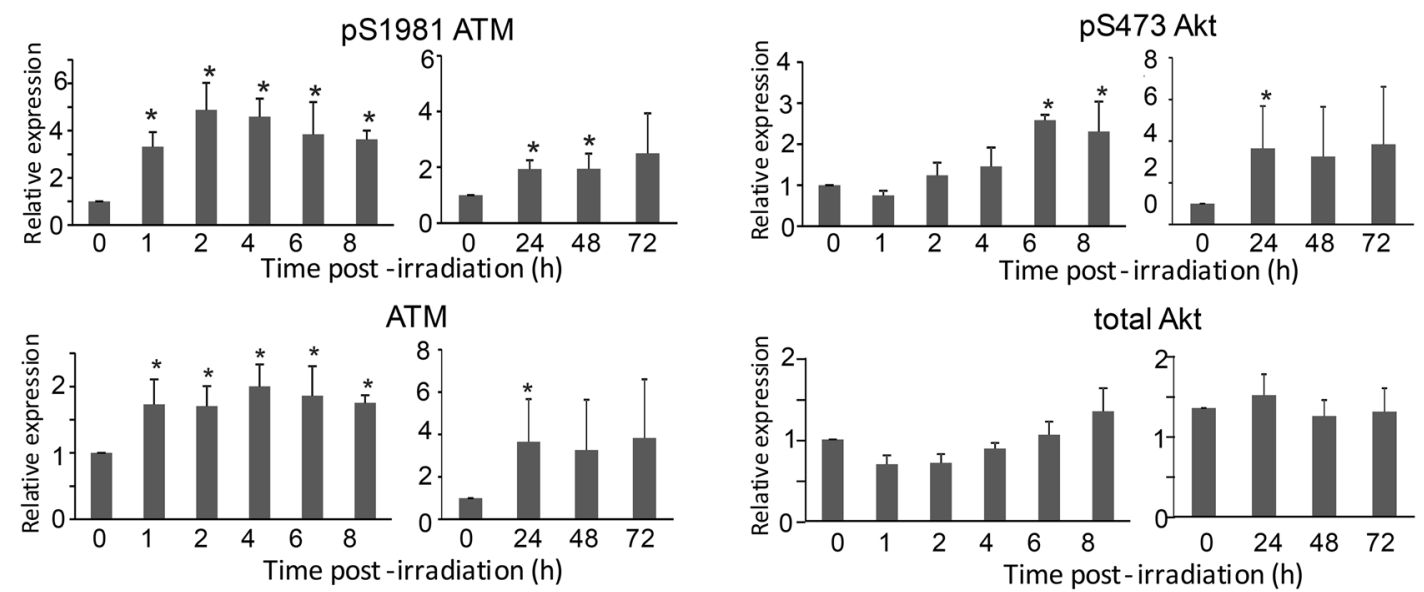

total Akt
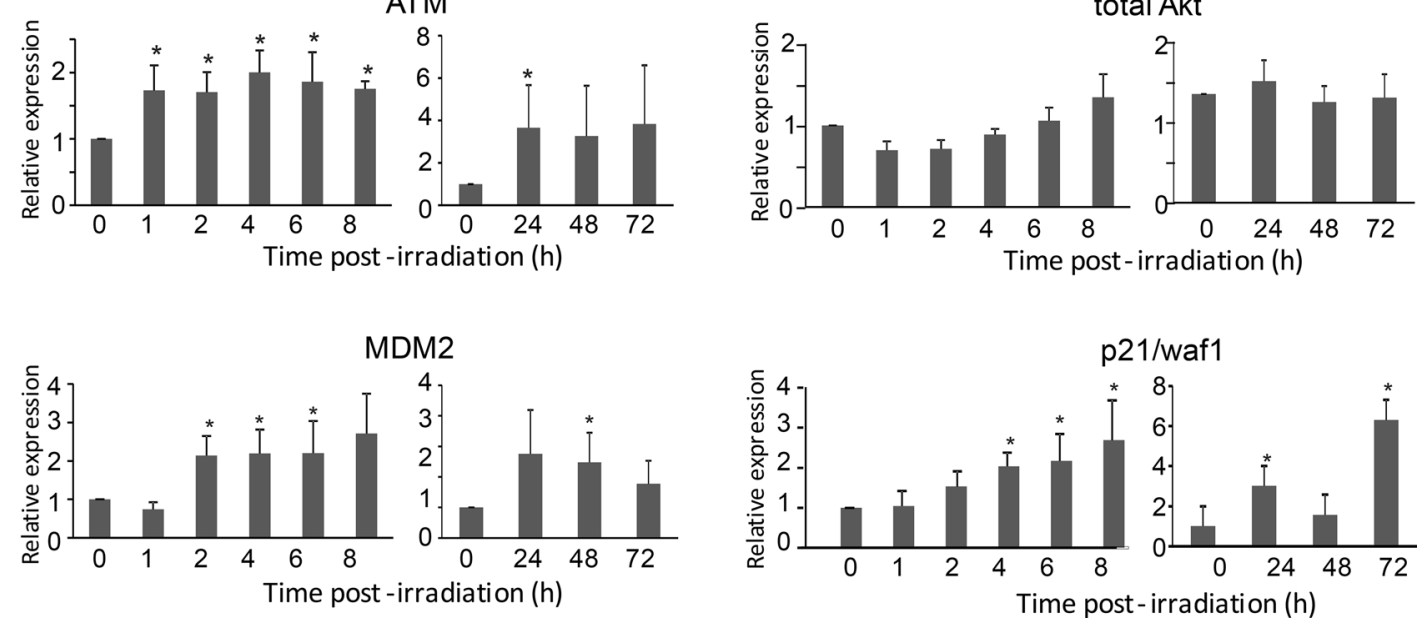

Figure 3. Changes in protein levels and phosphorylation in irradiated HLMVEC. HLMVEC were grown to $70 \%$ confluence and exposed to $10 \mathrm{~Gy} \mathrm{X}$-ray irradiation. Protein lysates were prepared at the indicated time points and used for western blotting for the indicated proteins and phospho-proteins. (a) Representative blots are shown from 3 independent experiments for (from top to bottom) pS1981 ATM, total ATM, pY908 IGF1R $\beta$, total IGF1R $\beta$, MDM2, pS473 Akt, total Akt, p53, p21/waf1, and $\beta$-actin. (b) Densitometry was performed for pS1981 ATM, total ATM, pS473 Akt, total Akt, MDM2, and p21/waf1. Graphs indicate means, normalized to $\beta$-actin protein levels, \pm SEM from 3 independent experiments. ${ }^{*}$ indicates $p<0.05$. 
a

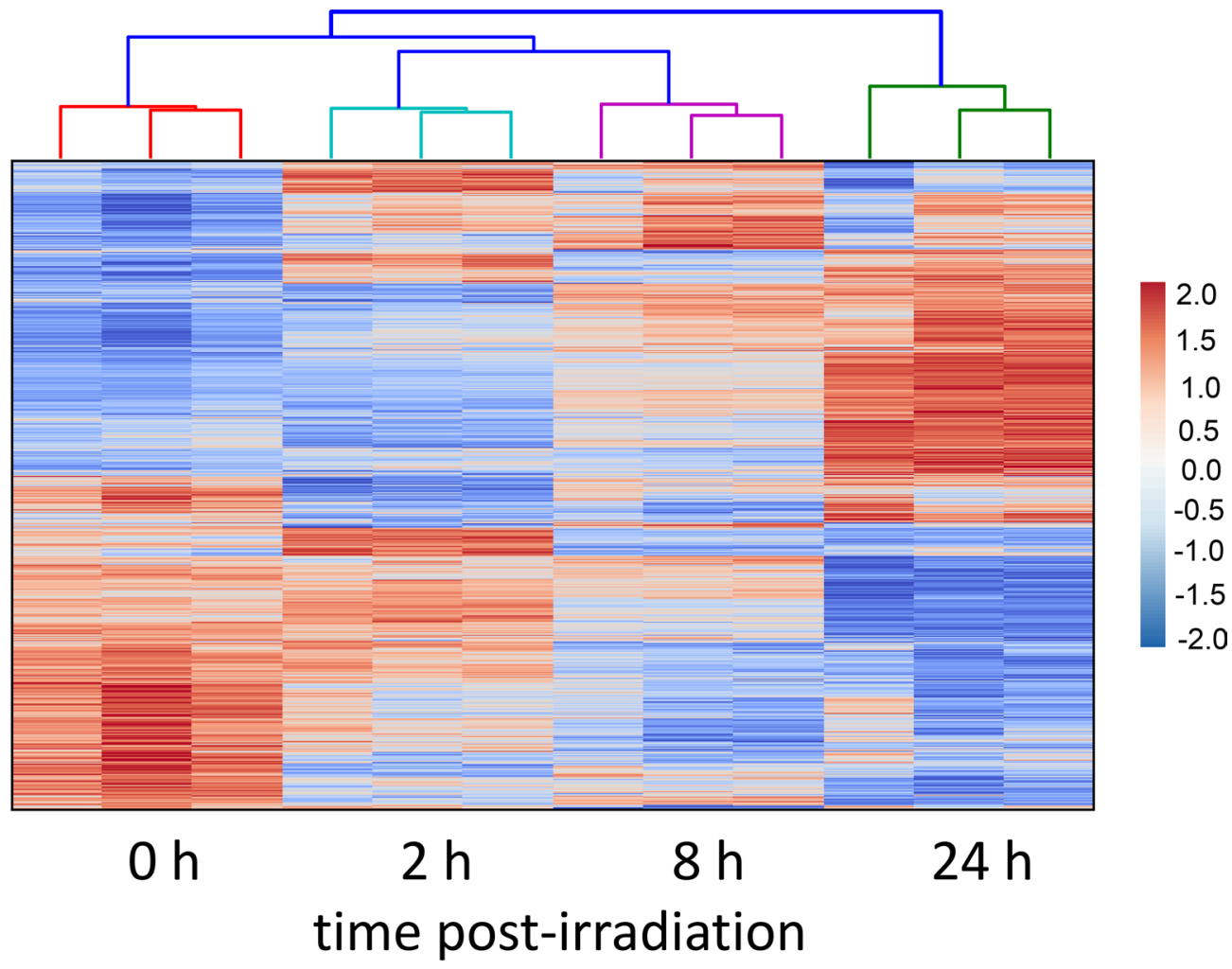

b

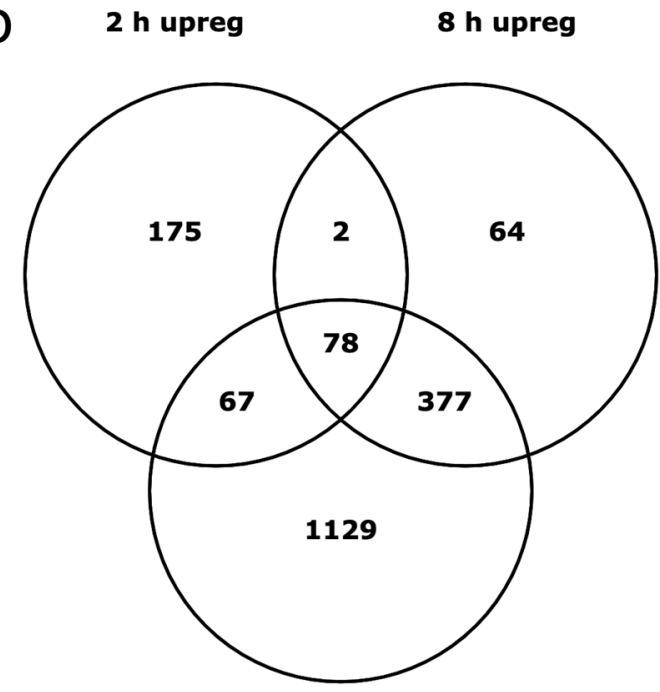

24 h upreg

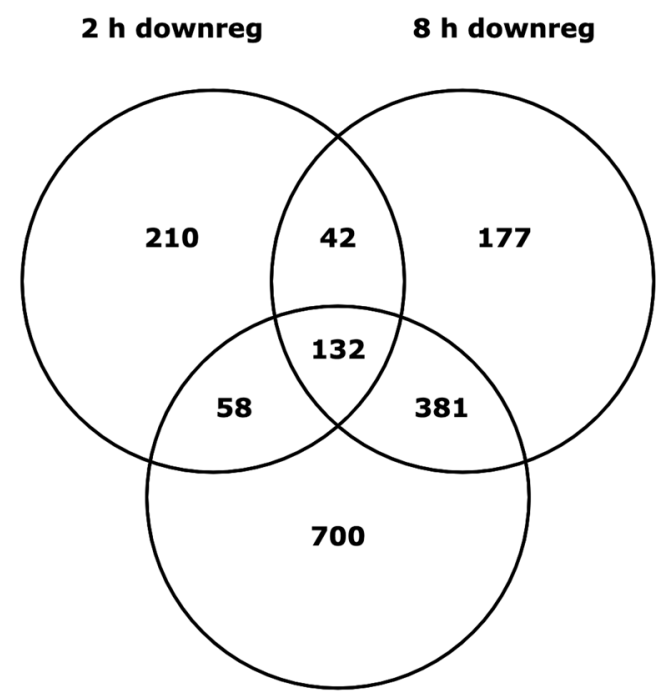

24 h downreg

Figure 4. Clustering and distribution of differentially expressed genes (DEG). HLMVEC were grown to 70\% confluence and exposed to $10 \mathrm{~Gy}$ X-ray irradiation. RNA was prepared at 2, 4, 6, 8 and 24 h post-irradiation and used for RNA-seq. (a) Heat map indicates distinct gene expression patterns at each time point postirradiation. Controls are non-irradiated samples. Included are genes differentially regulated over the $24 \mathrm{~h}$ time course, $q<0.05$. (b) Venn diagrams illustrate overlap of the number of DEG expressed at each time point for upregulated or downregulated genes, $\mathrm{q}<0.05$, fold change $>1.5$. Data was generated using RNA from three independent experiments.

followed by the cell cycle and tumor necrosis factor (TNF) and FoxO signaling pathways (Fig. 5d). GOrilla analysis identified enrichment of terms associated with hypoxia response, RNA processing, kinase activity, and cell cycle phase transition. The clusters, pathways, and terms enriched at $8 \mathrm{~h}$ suggest that the cells responded to 


\section{BP Cluster Enrichment}

a

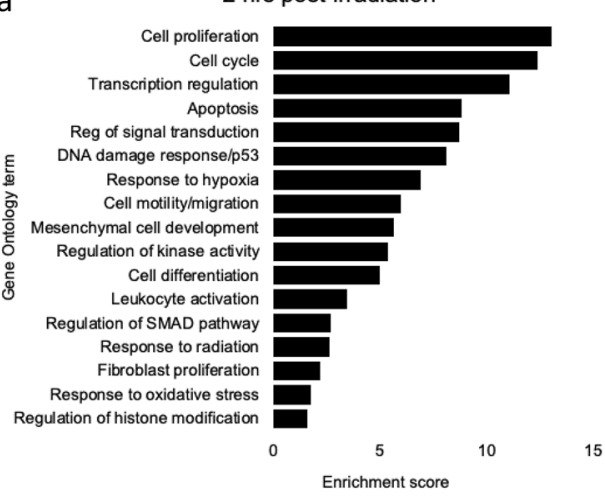

C

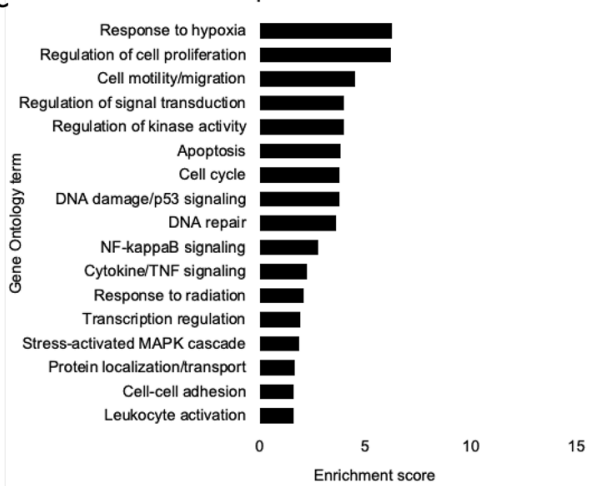

e

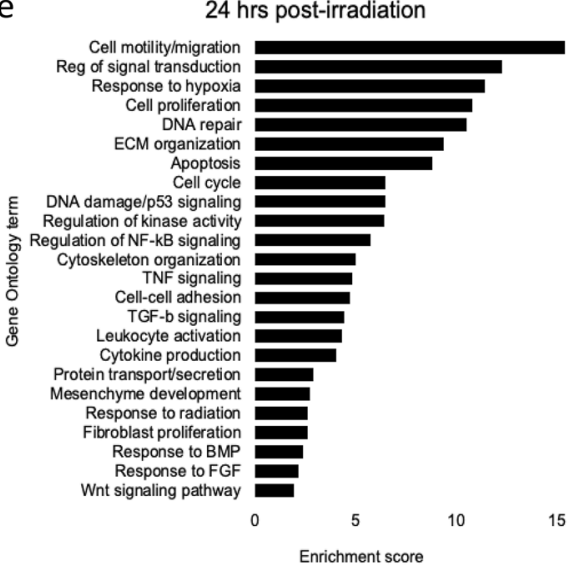

KEGG Pathway Enrichment
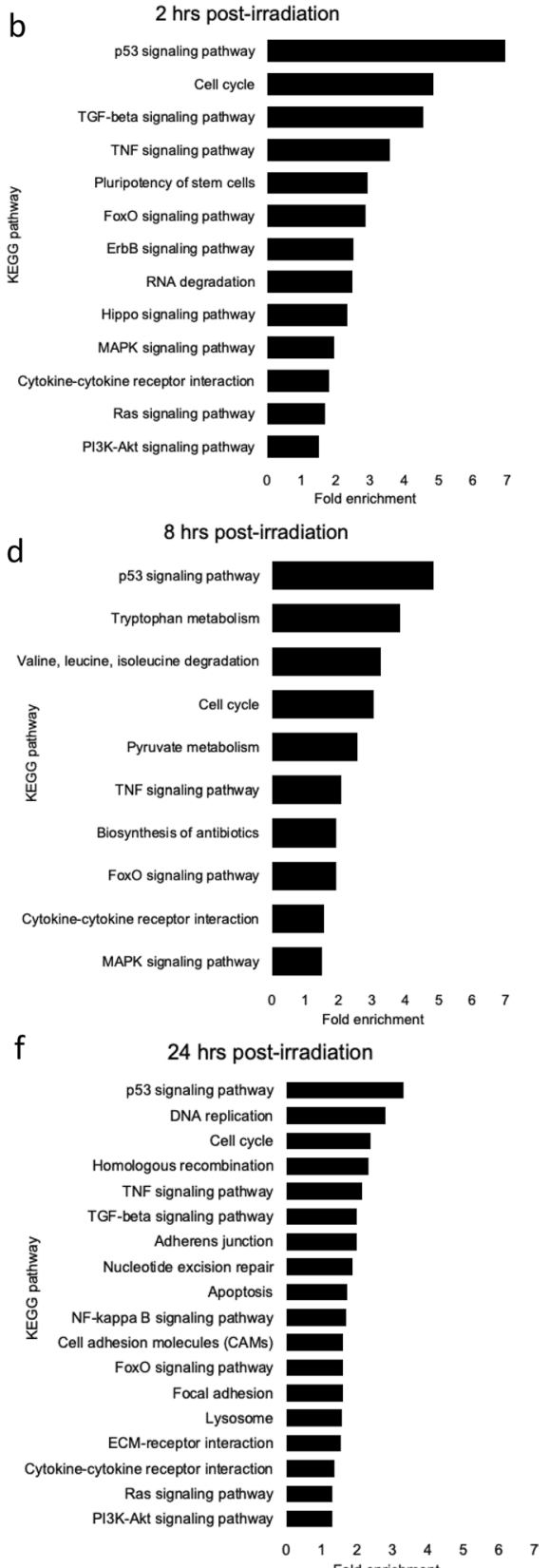

Figure 5. GO term cluster and KEGG pathway enrichment analyses of differentially expressed genes in HLMVEC following $10 \mathrm{~Gy} \mathrm{X}$-irradiation. HLMVEC were grown to $70 \%$ confluence and exposed to $10 \mathrm{~Gy} \mathrm{X}$-ray irradiation. RNA was prepared and used for RNA-seq. (a,b) $2 \mathrm{~h}$ post-irradiation. (c,d) $8 \mathrm{~h}$ post-irradiation. $(\mathbf{e}, \mathbf{f}) 24 \mathrm{~h}$ post-irradiation. DAVID (https://david.ncifcrf.gov) software was used for functional annotations. DEG $>1.5$-fold, $\mathrm{q}<0.05$. The enrichment is shown for both up- and down-regulated pathways. Data was generated using RNA from three independent samples.

radiation by arresting the cell cycle, possibly through p53 signaling, that may be coordinated with DNA repair and the induction of accelerated senescence through FoxO and TNF signaling pathways.

At $24 \mathrm{~h}$ post-irradiation, there was an increase in the numbers of regulated genes $(2,922$ genes $>1.5$-fold $[\mathrm{q} \leq 0.05])$ compared with prior time points, and with higher enrichment scores than at $8 \mathrm{~h}$. In addition to hypoxia, cell proliferation and cell cycle terms that were observed at other times, DAVID analysis of genes regulated at $24 \mathrm{~h}$ indicated that cell motility and migration, extracellular matrix (ECM) organization, cytoskeleton organization, and protein secretion processes were more prominent. The increased alterations in genes affecting structure, movement, and the exterior of the cell suggested a new phase of cellular response at $24 \mathrm{~h}$ (Fig. 5e). KEGG analysis showed that at $24 \mathrm{~h}$, p53 signaling, DNA replication, cell cycle, and homologous recombination were most enriched, however TNF and TGF- 3 pathways were also significant (Fig. 5f). GOrilla analysis also 


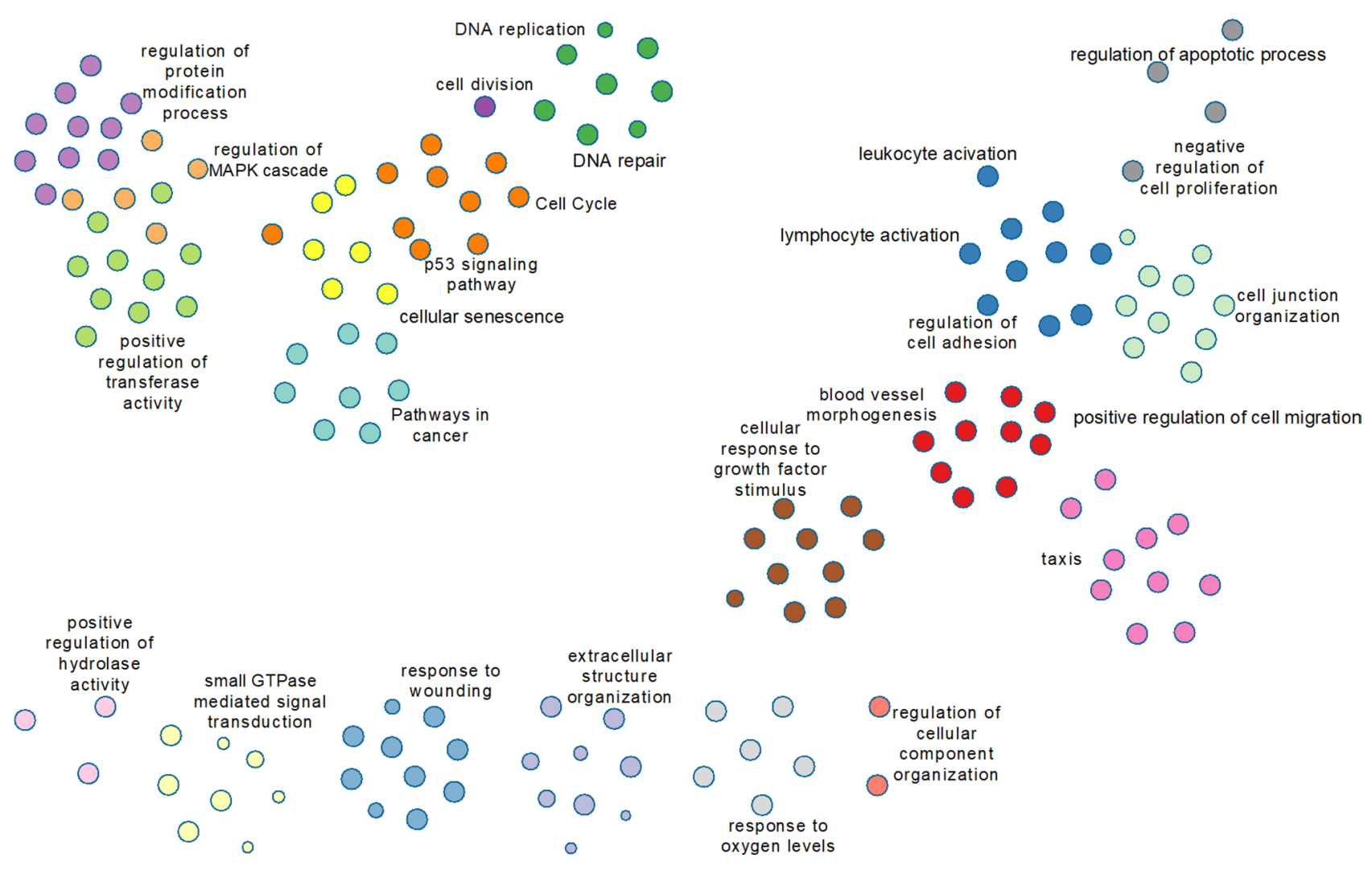

Figure 6. Visualization of clustered GO terms. Metascape (https://metascape.org ${ }^{46}$ ) was used to create an image of clustered GO terms present in the 1000 genes with the lowest q-value regardless of time point, Clusters, represented by colored circles, are grouped to aid in visualization of the relationships among the 1000 genes with the lowest q-value $(\mathrm{q} \leq 2.61 \mathrm{E}-37)$.

showed regulation of cell migration and adhesion, DNA damage response, replication and repair, focal adhesion assembly, and NF-kappaB transcription factor activity.

Metascape (https://metascape.org ${ }^{46}$ ) was used to create an image of clustered GO terms present in the 1000 genes with the lowest q-value regardless of time point (Fig. 6). This image allows us to visualize the important gene functions that are regulated in HLMVEC in response to $10 \mathrm{~Gy}$ irradiation.

Focused analysis of RNA-seq after $\mathbf{1 0}$ Gy X-irradiation. To further analyze the DEGs, we used $\mathrm{g}$ :Profiler, web based software that performs functional enrichment analysis, and a literature search to identify pathways in the 3000 genes with the lowest q-value $(\leq 1.18 \mathrm{E}-14)$. We identified four significant pathways activated following $10 \mathrm{~Gy}$ X-irradiation: cell cycle regulation; apoptosis; DNA damage response; and cellular senescence (Supplemental Table S2). Based on literature reports, we also found significant regulation of genes related to two additional processes: inflammation and endothelial-to-mesenchymal transition (EndMT) ${ }^{50}$. Focused heat maps were constructed using ClustVis that included genes regulated within each pathway to determine overall pathway activation or suppression over the experimental time course $\mathrm{e}^{45}$.

Cell cycle regulation. Radiation has a broad effect on the cell cycle in a wide variety of cell types ${ }^{21}$. Analysis of HLMVEC gene expression changes following radiation exposure identified 54 genes with roles in cell cycle regulation (Fig. 7a). Nine cyclin genes (CCNA1, CCNA2, CCNB1, CCNB2, CCND1, CCND2, CCNE1, CCNE2, and $\mathrm{CCNH}$ ) displayed distinct expression patterns in response to ionizing radiation. CCNA2, that promotes transition through $\mathrm{S} / \mathrm{G}_{2}$ and $\mathrm{G}_{2} / \mathrm{M}$, decreased 1.7 -fold at $24 \mathrm{~h}$. CCNB1 and CCNB2, that regulate progression through the $\mathrm{G}_{2} / \mathrm{M}$ transition, decreased at 2-6 h post-irradiation, but returned to near basal levels at $24 \mathrm{~h}$. In contrast $C C N D 1$ and $C C N D 2$, that regulate $\mathrm{G}_{1}$ phase transition, were elevated over full the time course, upregulated 1.9- and 4.5-fold at $24 \mathrm{~h}$ post-irradiation. $C C N E 1$ and $C C N E 2$, that regulate $\mathrm{G}_{1} / \mathrm{S}$ phase transition, were increased at $2 \mathrm{~h}$ (1.5- and 1.8-fold respectively), but then were downregulated by $24 \mathrm{~h}$ (2.4- and 3.9-fold respectively). Three cyclin-dependent kinases (CDKs) CDK1 and CDK2 were downregulated 1.6- and 1.5-fold at $24 \mathrm{~h}$. Cyclin-dependent kinase inhibitors $C D K N 1 A$ and $C D K N 2 B$, were upregulated over the entire time course, and increased 4.2- and 4.7-fold, respectively, at $24 \mathrm{~h}$. CDKN1B, CDKN2C, and CDKN2D, that control G $\mathrm{G}_{1}$ progression, were downregulated over the time course, decreasing 1.6- ,2.6-, and 2.5-fold, respectively, by $24 \mathrm{~h}$ postirradiation.

E2F genes encode transcription activators that control transcription of cell cycle genes ${ }^{51}$. In particular, $\mathrm{G}_{1}-\mathrm{S}$ phase transition requires $\mathrm{E} 2 \mathrm{~F}$ transcription factor activation. $E 2 F 1$ and $E 2 F 2$ transcriptional activators were 


\section{a Cell cycle}

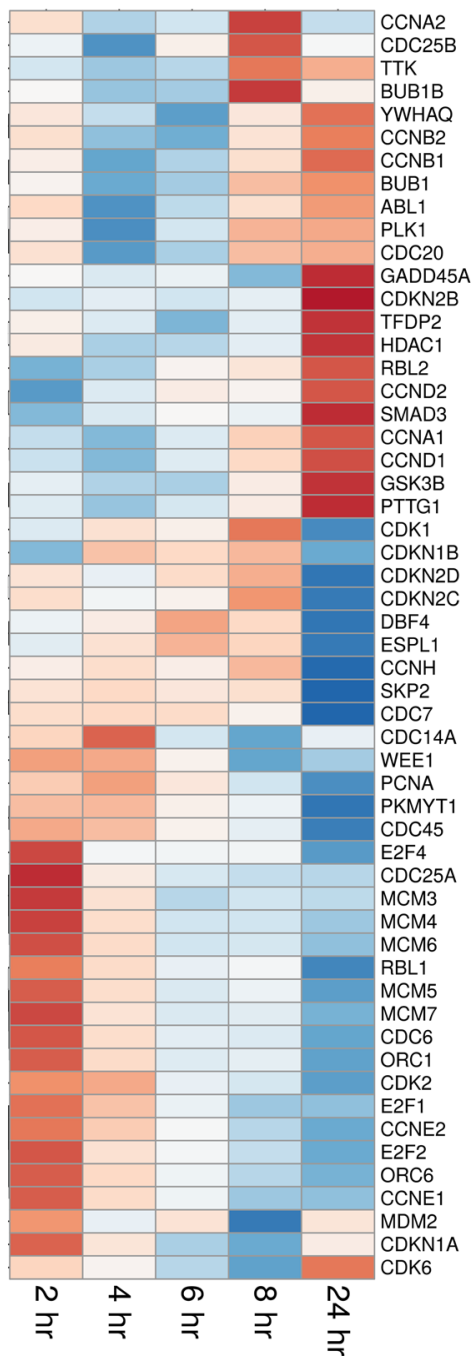

b Apoptosis

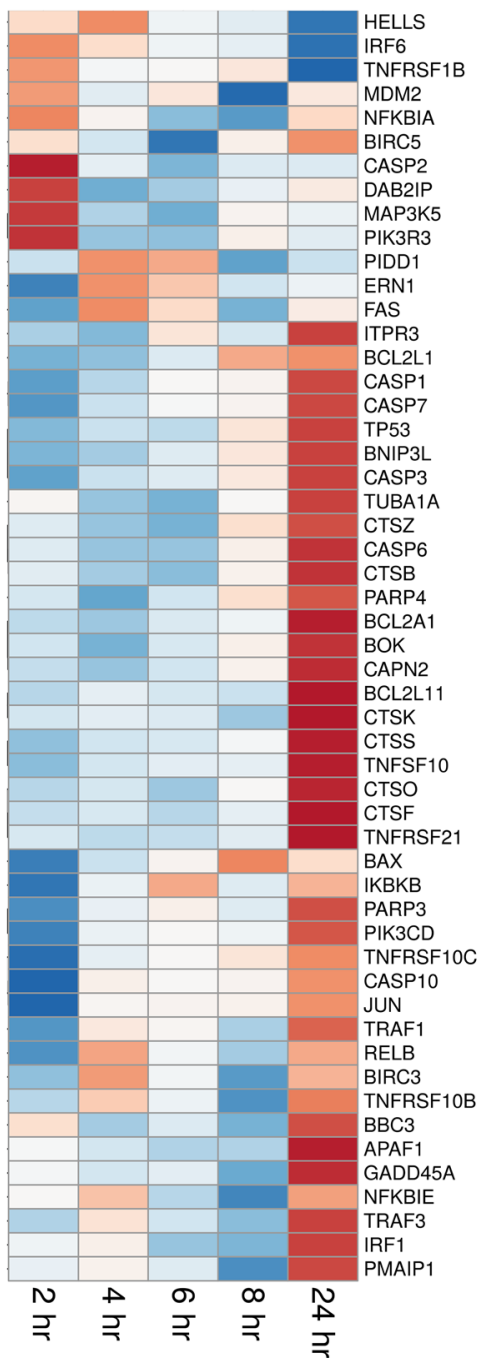

c DNA damage

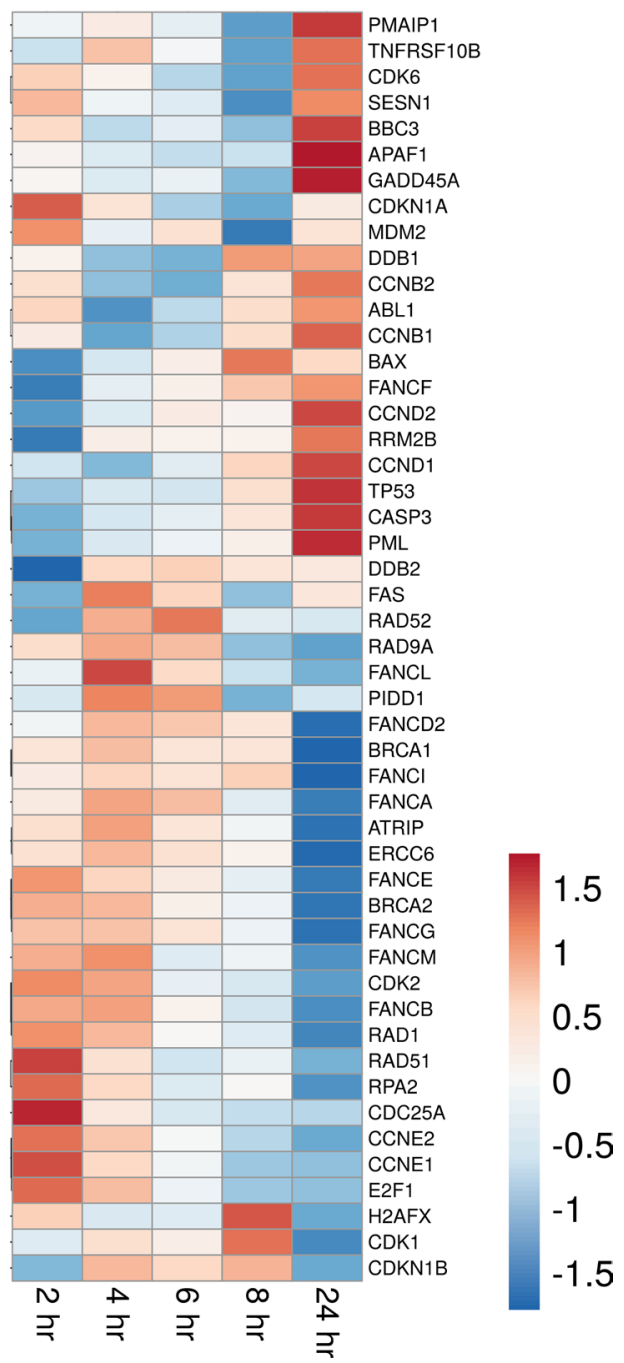

Figure 7. Heatmap of biological pathway gene expression in HLMVEC following radiation exposure. RNAseq was used to identify gene expression changes in HLMVEC following exposure to $10 \mathrm{~Gy}$ X-ray irradiation. ClustVis (https://biit.cs.ut.ee/clustvis) was used to generate heat maps. Rows are centered; unit variance scaling is applied to rows. Rows and columns are clustered using correlation distance and average linkage. Set of 3000 genes with lowest q-value was submitted to g:Profiler (https://biit.cs.ut.ee/gprofiler/) to identify pathways. Pathway heat maps indicate changes in gene expression compared to control at the post-irradiation time points indicated. (a) Cell cycle pathway, (b) Apoptosis pathway, (c) DNA damage pathway, (d) Inflammatory response pathway, (e) Senescence pathway, and (f) Endothelial to Mesenchymal Transition pathway. 

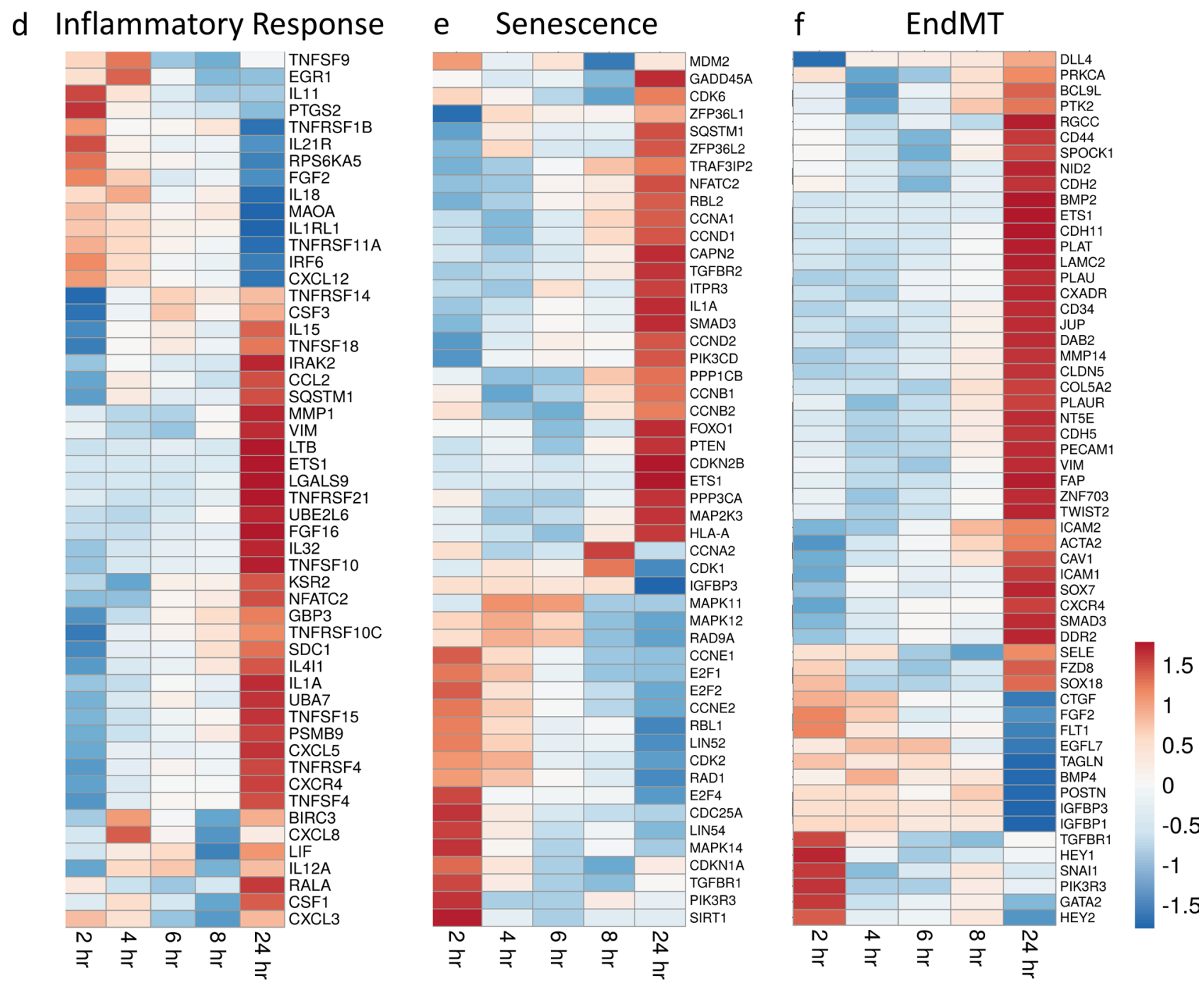

Figure 7. (continued)

initially upregulated (1.4- and 1.7-fold, respectively) and then downregulated (2.9-fold and 3.8-fold respectively) at $24 \mathrm{~h}$. E2F8, that regulates $\mathrm{G}_{1}$ to $\mathrm{S}$ phase progression, was downregulated 3.2-fold by $24 \mathrm{~h}$. Interestingly, the repressive E2F family member E2F4, which suppresses cyclin D expression, was downregulated 1.4-fold, correlating with the increased expression of cyclin D gene expression.

Two ORC subunit genes, ORC1 and ORC6, were downregulated 2.7- and 2.1-fold, respectively, at 24 h postirradiation. Expression of $M C M$ complex genes 3-7 also decreased through $24 \mathrm{~h}$ in a similar pattern. Additionally, our further investigation of the data showed that MCM2, MCM8, and MCM10 that also participate in DNA replication, although not identified in the program analysis, were also suppressed following X-irradiation.

Regulation of apoptosis. Pathway analysis showed that both pro- and anti-apoptotic proteins involved in the initiation of the extrinsic and intrinsic apoptotic pathways were regulated, with an early wave of apoptotic gene regulation at $2 \mathrm{~h}$, and a second wave of regulation at $24 \mathrm{~h}$ post-irradiation (Fig. $7 \mathrm{~b}$ ). The extrinsic pathway-related death receptors TNFRSF10B, TNFRSF21 and TNFRSF4 were increased 1.7-, 3.7-, and 10.7-fold respectively, at $24 \mathrm{~h}$. However, the anti-apoptotic TNFRSF10C, a decoy death receptor that does not contain a death domain, had early and sustained expression, and was increased 2- to 3.3-fold from 4 to $24 \mathrm{~h}$. Genes encoding TNF receptor ligands were also upregulated inclugin TNFSF4, TNFSF9, TNFSF10, TNFSF12, TNFSF13, TNFSF15, and TNFSF18 (3.6-, 4.0-, 4.2-, 1.5-, 1.5-, 44.0-, and 2.3-fold respectively). LTB, encoding a cytokine that binds a TNF receptor 3 (TNFRSF3) was upregulated 26.5-fold. Genes encoding anti-apoptotic proteins acting to counteract extrinsic apoptotic pathway signaling were also increased, including TNF Receptor Associated Factor 1 (TRAF1), a negative regulator of apoptosis signaling by TNFR superfamily members, increased 7.2-fold by $24 \mathrm{~h}$.

The Bcl 2 family of proteins are pro- or anti-apoptotic, depending upon their effects on cytochrome $c$ release from the mitochondrion. Genes encoding pro-apoptotic members of the Bcl-2 family were upregulated, including: $B B C 3, B C L 2 L 11, B C L 2$ Interacting Protein 3 Like $(B N I P 3 L)$, and BOK (5.2-, 6.9-, 3.2- and twofold, respectively) at $24 \mathrm{~h}$. However, at the same time, the anti-apoptotic $B C L 2 A 1$ gene was upregulated 3.5-fold. The 
transcript for BCL2L1 was upregulated 2- and 2.1-fold at $8 \mathrm{~h}$ and $24 \mathrm{~h}$, respectively, although alternative splicing can result in either a pro- or anti-apoptotic activity for this transcript.

We also observed mixed regulation of proteins required for downstream apoptotic signaling. Apoptotic protease activating factor 1 (APAF1) required for caspase activation, was increased 1.6-fold at $24 \mathrm{~h}$. The gene for Jun proto-oncogene, AP-1 transcription factor subunit (JUN), also involved in caspase activation, was downregulated at $2 \mathrm{~h}$, but increased 2.2-fold at $24 \mathrm{~h}$. Cathepsins, lysosomal proteolytic enzymes that can directly or indirectly activate caspases, were also upregulated by radiation ${ }^{52}$ : CTSK, CTSO, and CTSS were upregulated 3-, 2.2-, and 4.1-fold, respectively, at $24 \mathrm{~h}$. Caspases $1,3,6,7$, and 10 were upregulated at $24 \mathrm{~h}$ post-irradiation (4.6-, 1.9-, 1.6-, $2.6-$, and 1.5 -fold, respectively). Caspase 2 was upregulated 1.3 -fold at $2 \mathrm{~h}$ post-irradiation, but was subsequently downregulated. Our findings of mixed regulation of apoptotic genes is consistent with our finding of only very low levels of apoptosis in HLMVEC in response to radiation.

Regulation of DNA damage response. GO analysis identified 48 genes associated with DNA damage that were regulated $>1.5$-fold (Fig. 7c). Cyclins and their related kinases and kinase inhibitors make up 25\% of the DNA damage response genes; these were described in Cell cycle regulation section, above. The data set also includes genes encoding DNA damage response and repair enzymes.

Radiation increased mRNA levels for genes in the excision repair pathway including DNA damage binding protein 1 (DDB1), its partner DDB2, and excision repair cross-complementing rodent repair deficiency (ERCC6), all critical for DNA excision repair, upregulated 1.6-, 2.2-, and 3.3-fold, respectively, throughout the time course. Growth arrest and DNA damage inducible 45A (GADD45A), an early DNA damage response gene with multiple functions in cell cycle and survival, was increased 3.4-fold at $24 \mathrm{~h}$.

Interestingly, genes encoding proteins for homologous recombination repair and long-patch excision repair were downregulated. Homologous recombination repair genes that were downregulated included radiation 51 (RAD51) and RAD52, both reduced 1.5-fold at 24 h. Breast cancer 1 (BRCA1) and BRCA2, that also contribute homologous recombination repair, were downregulated 1.5- and 1.8-fold at $24 \mathrm{~h}$. RAD1 and RAD9A, involved in long-patch base excision repair, were downregulated 2.5- and 1.6-fold. Additionally, 9 members of the Fanconi anemia complementation group, involved in intra-strand crosslinking repair, were downregulated from 1.3- to 2.8-fold at later time points. These data suggest that HMLVEC utilized only specific pathways for DNA repair.

Radiation-induced inflammatory response. Inflammation is a critical in vivo response to radiation exposure $^{13,53}$. The normal function of the immune-inflammatory response is to prevent infection, instigate removal of dead or damaged cells, and initiate normal tissue repair ${ }^{13}$. However, chronic activation of inflammation post-irradiation can lead to an amplification of initial radiation damage to areas outside of the radiation field, leading to fibrosis and tissue necrosis ${ }^{13,53}$. We identified inflammation-related 52 genes with altered expression. Of these, 32 genes were upregulated $>$ two-fold, and 17 were upregulated $>$ four-fold at $24 \mathrm{~h}$ (Fig. $7 \mathrm{~d}$ ). These genes included transcription factors, interleukins (ILs), and chemokine receptors and ligands. Tumor necrosis factor receptors and ligands were discussed in the section on apoptosis (see above).

Transcription factors ETS1 and NFATC2 that regulate cytokine expression were upregulated 3.3- and 7.2-fold at $24 \mathrm{~h}$. We identified 19 interleukin (IL) genes, targets of ETS1 and NFATC2, that were significantly regulated from 2 to $6 \mathrm{~h}$ post-irradiation. Interleukin $1 \mathrm{~A}(I L 1 \mathrm{~A})$, a potent pro-inflammatory cytokine, was upregulated 8.5fold at $24 \mathrm{~h}$. T cell regulatory cytokine LIF was upregulated 2.6-fold at $2 \mathrm{~h}$ and 4.2 -fold at $24 \mathrm{~h}$. CSF1, macrophage colony-stimulating factor, was also upregulated 3.9-fold at $24 \mathrm{~h}$. Chemoattractants for immune cells were also increased. CXCR4, that mediates migration of leukocytes, was increased 8.9-fold at $24 \mathrm{~h}$. CXCL12, that mediates migration of lymphocytes and macrophages, was upregulated early, but was steadily reduced to 9.5 -fold decrease at $24 \mathrm{~h}$. CCL2, a monocyte, T cell, and dendritic cell attractant, was upregulated sixfold at $24 \mathrm{~h}$.

Senescence related gene expression induced by radiation. GO pathway analysis identified 50 genes involved in senescence (Fig. 7e). As for apoptosis where both pro- and anti-apoptotic genes were regulated, our data set for senescence also showed both pro- and anti-senescence gene regulation. Senescence pathway genes overlap with cell cycle regulation genes and DNA damage genes, previously discussed (see above sections). Interestingly, inflammation-related genes involved in senescence are some of the most upregulated in our data set; the inflammatory genes regulated by radiation were discussed in the prior section.

Insulin-like growth factor (IGF) signaling has been demonstrated to play a major role in age-related senescence as well as accelerated senescence ${ }^{54}$. Although immediate activation of the IGF1 receptor is associated with the induction of senescence in cultured cells following biological stress, the IGF-binding proteins (IGFBPs) that affect the half-lives of IGFs and alter their interactions with cell surface receptors are associated with both proand anti-senescent activities ${ }^{24,54}$. The anti-senescence protein IGFBP $1^{55}$ was downregulated 19 -fold. IGFBP3, that can mediate proliferation, apoptosis, or senescence ${ }^{56,57}$, was also highly downregulated ( $>15$-fold) at $24 \mathrm{~h}$. In contrast, IGFBP6, important in the progression of senescence, was upregulated 1.7-fold at $24 \mathrm{~h}$. IGFBP7, that is secreted by senescent cells and can induce senescence in neighboring cells ${ }^{58}$, was also upregulated 1.7 -fold at $24 \mathrm{~h}$.

Radiation regulation of endothelial-to-mesenchymal transition. EndMT is the process in which ECs lose their normal characteristics and exhibit a mesenchymal-like phenotype, including loss of cell-cell junctions, increased migration, and increased invasive capacity ${ }^{50,59}$. EndMT is not currently described as a distinct pathway in GO terms, so we conducted a literature search to identify genes associated with EndMT ${ }^{60,61}$. We found 64 genes in our data set that were regulated $>1.5$-fold in at least one time point (Fig. $7 f$ ). Forty-four of the genes were upregulated at $24 \mathrm{~h}, 28$ of them $>$ twofold. Twenty-two genes were downregulated at $24 \mathrm{~h}$, seven $>$ twofold. 
Consistent with mesenchymal transition, EC markers were suppressed and mesenchymal (MC) markers were upregulated within $24 \mathrm{~h}$ post-irradiation. EC markers FLT1 was downregulated 2.8 -fold at $24 \mathrm{~h}$. Other markers, $P E C A M 1$, an intercellular junction adhesion molecule and $C D H 5$, a cadherin that controls cohesion and organization of intercellular junctions, were upregulated 2.2-fold at $24 \mathrm{~h}$ suggesting radiation effects cell-cell adhesion. Several genes encoding cell surface proteins associated with recruitment of inflammatory cells, that were associated with EndMT in other systems, were also increased: ICAM1 and SELE (2.1- and 6.2-fold respectively). The mesenchymal cell surface markers ACTA2, VIM, CDH2 and CDH1 $1^{62}$ were upregulated 5.4-, 6.1-, 2.3- and 4.6-fold, respectively, at $24 \mathrm{~h}$. Surprisingly, although we observed significant upregulation of mesenchymal markers, we also observed simultaneous upregulation of endothelial markers PECAM1 and CDH5 at $24 \mathrm{~h}$ post-irradiation (as stated above).

Cytokines that contribute to EndMT and intracellular downstream signaling molecules were upregulated following HLMVEC irradiation. BMP2 was upregulated 11.7 -fold at $24 \mathrm{~h}$ post-irradiation. Interestingly, BMP4, shown to inhibit epithelial-to-mesenchymal transition ${ }^{63}$, was downregulated 4.4 -fold at $24 \mathrm{~h}$ post-irradiation. FGF2, HEY1, and HEY2 family members are negative regulators of EndMT were downregulated at $24 \mathrm{~h}$. TWIST2, FZD8, SPOCK1, DAB2, SMAD1 and SMAD3, signaling molecules that positively regulate EndMT ${ }^{64}$, were upregulated 2-, 2.2-, 1.7-, 2.5-, 4- and 3.3-fold at $24 \mathrm{~h}$. Additionally, EndMT signaling protein SNAI1, and its stabilizer DDR2, were upregulated 1.1- and 1.84-fold at $24 \mathrm{~h}$. SOX7 and SOX18, transcription factors involved in regulating EndMT gene expression $^{65}$, were increased 3.1- and 1.9-fold at $24 \mathrm{~h}$ post-irradiation. At $24 \mathrm{~h}$ post-irradiation, DLL4, a negative regulator of EndMT signaling, was downregulated 2.7-fold.

ECM proteins and proteases that degrade the extracellular matrix (ECM) were altered by radiation in HMLVECs. COL5A2, a protein characteristic of mesenchymal ECM secretion, was upregulated 1.9-fold at $24 \mathrm{~h}$. Nine matrix metalloproteinase (MMP) genes were regulated >1.5-fold: Collagenases MMP1, MMP2 and MMP19, stromelysins MMP10 and MMP11, and membrane anchored MMP14 and MMP15 were upregulated ${ }^{66,67}$. At this same time point matrilysin $M M P 7$ and membrane anchored MMP16 were downregulated (1.5- to 2.5-fold). $P L A U, P L A T$, and FAP, encoding secreted serine proteases that degrade the ECM, release of growth factors and cytokines, and tissue cell migration, were upregulated 16.6-, 8.8-, 2.4-fold fold at $24 \mathrm{~h}$.

\section{Discussion}

Radiation injury to the vasculature is a key factor in delayed radiation damage to tissues. Damage to the endothelium can result in reduced blood flow and lower oxygen perfusion of the tissues ${ }^{9,16,17}$. Additionally, increased permeability of the microvascular endothelial barrier results in increased fluid extravasation, tissue edema, and increased inflammation of the tissues ${ }^{10,15}$. Thus, microvascular damage is considered to be a critical component for persistent radiation tissue damage and for the expansion of injury outside of the original field of radiation exposure. Here we examined an early time course of gene expression changes in cultured primary HLMVEC to gain insight into the pathways activated by acute radiation exposure. An overall summary of our GO analysis shows the regulation of KEGG and Wiki pathways, including cell cycle, apoptosis, DNA damage, and senescence (Fig. 7). We perused the literature for genes that have roles in EndMT and the inflammatory response, and interrogated our RNA-seq data for relevant gene regulation of those pathways. The time course of gene expression shows the coordination of these complex, yet interdependent responses to X-irradiation.

Regulation of genes regulating the cell cycle was notable within $2 \mathrm{~h}$ following irradiation. The majority of the genes identified in the cell cycle pathway were cyclin-related genes, origin recognition complex (ORC) subunit genes, and minichromosome maintenance complex components (MCM). Cyclins, cell division cycle genes, cyclin dependent kinases, and cyclin dependent kinase inhibitors cooperate to regulate the cell cycle progression and transitions. ORC protein subunits are required for assembly of the pre-replication complex for initiation of DNA replication during $\mathrm{S}$ phase of the cell cycle and serves as a platform at the origin of replication for the assembly of initiation factors and MCM proteins. MCMs control the cell cycle by regulating DNA replication ${ }^{68}$. The data show a complex pattern of regulation of cell cycle controlling genes, and overall suggest a downregulation of genes required for DNA replication and for $S, G_{2}$, and $M$ phase progression, and at the same time an increase in expression of genes encoding proteins involved in early $\mathrm{G}_{1}$ progression.

DNA damage response for the repair of single- and double-stranded breaks is critical for cell survival following radiation exposure. Multiple pathways of DNA repair have been recognized, including non-homologous end joining, homologous recombination, base excision repair, nucleotide excision repair, mismatch repair, the Fanconi anemia pathway, which corrects DNA intra-strand crosslinks, and DNA demethylating enzymes ${ }^{47,69}$. DNA repair activities are closely coordinated with cell cycle regulation, which is hypothesized to allow the time for DNA repair enzyme activity and to prevent the proliferation of cells with mutations or chromosomal aberrations $s^{70}$. We observed the activation of DNA damage response protein ATM within 15-30 min post-irradiation, with other DNA damage response genes upregulated 2-24 h post-irradiation, consistent with rapid and sustained DNA damage response.

Following the interruption of the cell cycle in the presence of DNA damage, cells may undergo a variety of responses including necrosis, apoptosis, or senescence. We did not observe significant necrosis in our biological assays, and we detected only low levels of apoptosis. However, we observed the activation of a significant number of pro- and anti-apoptotic genes with early regulation of both pathways at $2 \mathrm{~h}$, followed by a second wave of activation of genes in both pathways at $24 \mathrm{~h}$ including genes for both the intrinsic and extrinsic apoptotic pathways ${ }^{71}$. The extrinsic pathway is usually triggered by activation of the death receptor family, including Fas receptor, and tumor necrosis factors activated by soluble or membrane-bound ligands ${ }^{72,73}$. In contrast, in the intrinsic apoptotic pathway various stimuli trigger the release of cytochrome $c$ from the mitochondria, a process that can be regulated by pro- and anti-apoptotic members of the Bcl-2 protein family. In both apoptotic pathways, caspase proteases are activated, leading to DNA cleavage and disintegration of cellular structures ${ }^{74}$. The mixed 
gene regulation that we observed for pro- and anti-apoptotic genes in both the intrinsic and extrinsic apoptosis pathways suggests that cells may be receiving multiple conflicting signals for survival and programmed death. This is in agreement with our findings of low levels of apoptosis from 24 to $72 \mathrm{~h}$ post-irradiation. Ultimately, the integrated response to gene expression changes in the apoptosis pathway appears to result in HLMVEC cell survival.

Our results indicate several groups of senescence-related genes are highly regulated in response to $10 \mathrm{~Gy}$ $\mathrm{X}$-irradiation. Normal cells undergo an ageing process that induces irreversible replicative arrest ${ }^{54,75}$. Genotoxic stress and other stressors can cause the cell to permanently exit the cell cycle, resulting in accelerated senescence ${ }^{54,75,76}$. An increasing body of evidence suggests that induction of cellular senescence by ionizing radiation may be a driver of the pathogenesis of RILI ${ }^{77}$. The senescent phenotype is characterized by a variety of physiological alterations including changes in the production of extracellular matrix proteins, cell-cell connectivity, resistance to apoptosis, and the secretion of pro-inflammatory cytokines and factors ${ }^{78}$. Senescence signaling pathways overlap with cell cycle regulation and DNA damage response, since response to genotoxic stress, such as is induced by radiation exposure, can lead to DNA damage response that induces a pause of the cell cycle as an initial step in DNA repair, and failed DNA repair can result in senescence ${ }^{54}$. Insulin-like growth factor (IGF) signaling has been demonstrated to play a major role in age-related senescence as well as accelerated senescence $^{54}$, although we did not observe IGFR activation in the HLMVEC.

The use of GO and KEGG for the analysis of RNA-seq data is limited by the molecular functions, biological processes, and cellular components that have been annotated. Because EndMT is not currently identified in GO terms, we used published findings to identify EndMT associated genes. EndMT process plays a role in organ development and in adult wound healing ${ }^{79}$. Dysregulation of EndMT is associated with the secretion of abnormal ECM in fibrotic organ diseases and in tumor microenvironments where it is believed to contribute to cancer progression and metastasis ${ }^{59,79,80}$. Signaling transduction cascades that contribute to EndMT include those induced by TGF- $\beta$ family members, Notch, and Wnt ligands, oxidative stress, and inflammation ${ }^{79}$. MMPs are important in a variety of developmental processes including mediation of cell-cell adhesion, tissue remodeling, cell migration, and proliferation ${ }^{81}$. Our identification of EndMT in the biological response to radiation in HLMVEC may indicate that these cells can play a role in fibrotic remodeling following radiation exposure. Further investigation of EndMT may help to determine whether this pathway can be inhibited or modulated to reduce delayed tissue injuries following radiation exposure.

Together, our data indicate a complex and integrated regulation of biological processes leading mostly to cellular senescence, a low levels of apoptosis, increased inflammation, and EndMT. Further investigation of these pathways may lead to the identification of targets for prevention, mitigation and treatment of radiation injury to normal tissues.

Received: 1 April 2021; Accepted: 6 December 2021

Published online: 20 December 2021

\section{References}

1. Lu, L. et al. Radiation-induced lung injury: latest molecular developments, therapeutic approaches, and clinical guidance. Clin. Exp. Med. 19, 417-426 (2019).

2. Hanania, A. N., Mainwaring, W., Ghebre, Y. T., Hanania, N. A. \& Ludwig, M. Radiation-induced lung injury: assessment and management. Chest 156, 150-162 (2019).

3. Huang, Y., Zhang, W., Yu, F. \& Gao, F. The cellular and molecular mechanism of radiation-induced lung injury. Med. Sci. Monit. 23, 3446-3450 (2017).

4. Wirsdorfer, F. \& Jendrossek, V. Modeling DNA damage-induced pneumopathy in mice: insight from danger signaling cascades. Radiat. Oncol. 12, 142 (2017).

5. Zhou, C. et al. Modeling and multiscale characterization of the quantitative imaging based fibrosis index reveals pathophysiological, transcriptome and proteomic correlates of lung fibrosis induced by fractionated irradiation. Int. J. Cancer. 144, 3160-3173 (2019).

6. Bentzen, S. M., Skoczylas, J. Z. \& Bernier, J. Quantitative clinical radiobiology of early and late lung reactions. Int. J. Radiat. Biol. 76, 453-462 (2000).

7. Uozaki, H. et al. The pathology of multi-organ involvement: two autopsy cases from the Tokai-mura criticality accident. BJR Supplement/BIR. 27, 13-16 (2005).

8. Baranov, A. E., Selidovkin, G. D., Butturini, A. \& Gale, R. P. Hematopoietic recovery after 10-Gy acute total body radiation. Blood 83, 596-599 (1994).

9. Trott, K. R., Herrmann, T. \& Kasper, M. Target cells in radiation pneumopathy. Int. J. Radiat. Oncol. Biol. Phys. 58, 463-469 (2004).

10. Zhao, J. et al. Thoracic radiation-induced pleural effusion and risk factors in patients with lung cancer. Oncotarget 8, 97623-97632 (2017).

11. Hewlett, J. C., Kropski, J. A. \& Blackwell, T. S. Idiopathic pulmonary fibrosis: epithelial-mesenchymal interactions and emerging therapeutic targets. Matrix Biol. 71-72, 112-127 (2018).

12. Korpela, E. \& Liu, S. K. Endothelial perturbations and therapeutic strategies in normal tissue radiation damage. Radiat. Oncol. 9, 266 (2014).

13. Guipaud, O. et al. The importance of the vascular endothelial barrier in the immune-inflammatory response induced by radiotherapy. Br. J. Radiol. 91, 20170762 (2018).

14. Dimitrievich, G. S., Fischer-Dzoga, K. \& Griem, M. L. Radiosensitivity of vascular tissue. I. Differential radiosensitivity of capillaries: a quantitative in vivo study. Radiat. Res. 99, 511-535 (1984).

15. Yarnold, J. \& Brotons, M. C. Pathogenetic mechanisms in radiation fibrosis. Radiother. Oncol. 97, 149-161 (2010).

16. Fleckenstein, K. et al. Temporal onset of hypoxia and oxidative stress after pulmonary irradiation. Int. J. Radiat. Oncol. Biol. Phys. 68, 196-204 (2007).

17. Roth, N. M., Sontag, M. R. \& Kiani, M. F. Early effects of ionizing radiation on the microvascular networks in normal tissue. Radiat. Res. 151, 270-277 (1999).

18. Pober, J. S. \& Sessa, W. C. Evolving functions of endothelial cells in inflammation. Nat. Rev. Immunol. 7, 803-815 (2007).

19. Hallahan, D. E. et al. Spatial and temporal control of gene therapy using ionizing radiation. Nat. Med. 1, 786-791 (1995). 
20. Kabacik, S. \& Raj, K. Ionising radiation increases permeability of endothelium through ADAM10-mediated cleavage of VEcadherin. Oncotarget 8, 82049-82063 (2017).

21. Panganiban, R. A., Snow, A. L. \& Day, R. M. Mechanisms of radiation toxicity in transformed and non-transformed cells. Int. J. Mol. Sci. 14, 15931-15958 (2013).

22. Lu, F., Li, Y. Q., Aubert, I. \& Wong, C. S. Endothelial cells regulate p53-dependent apoptosis of neural progenitors after irradiation. Cell Death Dis. 3, e324 (2012).

23. Roos, W. P. \& Kaina, B. DNA damage-induced cell death: from specific DNA lesions to the DNA damage response and apoptosis. Cancer Lett. 332, 237-248 (2013).

24. Panganiban, R. A. \& Day, R. M. Inhibition of IGF-1R prevents ionizing radiation-induced primary endothelial cell senescence. PLOS ONE 8, e78589 (2013).

25. Piera-Velazquez, S., Mendoza, F. A. \& Jimenez, S. A. Endothelial to mesenchymal transition (EndoMT) in the pathogenesis of human fibrotic diseases. J. Clin. Med. 5, 45 (2016).

26. Piera-Velazquez, S. \& Jimenez, S. A. Endothelial to mesenchymal transition: role in physiology and in the pathogenesis of human diseases. Physiol. Rev. 99, 1281-1324 (2019).

27. Daher, R. \& Karim, Z. Iron metabolism: State of the art. Transfus Clin Biol. 24, 115-119 (2017).

28. Choi, S. H. et al. HSPB1 Inhibits the endothelial-to-mesenchymal transition to suppress pulmonary fibrosis and lung tumorigenesis. Cancer Res. 76, 1019-1030 (2016).

29. Cao, T. et al. H19/TET1 axis promotes TGF-beta signaling linked to endothelial-to-mesenchymal transition. FASEB J. 34, 8625$8640(2020)$

30. Panganiban, R. A., Mungunsukh, O. \& Day, R. M. X-irradiation induces ER stress, apoptosis, and senescence in pulmonary artery endothelial cells. Int. J. Radiat. Biol. 89, 656-667 (2013).

31. Schmittgen, T. D. \& Livak, K. J. Analyzing real-time PCR data by the comparative C(T) method. Nat. Protoc. 3, 1101-1108 (2008).

32. Pfaffl, M. W. A new mathematical model for relative quantification in real-time RT-PCR. Nucleic Acids Res. 29, e45 (2001).

33. Wang, K. et al. MapSplice: accurate mapping of RNA-seq reads for splice junction discovery. Nucleic Acids Res. 38, e178 (2010).

34. Anders, S., Pyl, P. T. \& Huber, W. HTSeq-a Python framework to work with high-throughput sequencing data. Bioinformatics 31, 166-169 (2015).

35. Wang, L., Wang, S. \& Li, W. RSeQC: quality control of RNA-seq experiments. Bioinformatics 28, 2184-2185 (2012).

36. Li, H. et al. The Sequence Alignment/Map format and SAMtools. Bioinformatics 25, 2078-2079 (2009).

37. Danecek, P. et al. Twelve years of SAMtools and BCFtools. Gigascience. 10, giab008 (2021).

38. Kumar, P. et al. Comparative RNA-seq analysis reveals dys-regulation of major canonical pathways in ERG-inducible LNCaP cell progression model of prostate cancer. Oncotarget 10, 4290-4306 (2019).

39. Love, M. I., Huber, W. \& Anders, S. Moderated estimation of fold change and dispersion for RNA-seq data with DESeq2. Genome Biol. 15, 550 (2014).

40. Huang, D. W., Sherman, B. T. \& Lempicki, R. A. Systematic and integrative analysis of large gene lists using DAVID bioinformatics resources. Nat. Protoc. 4, 44-57 (2009).

41. da Huang, W., Sherman, B. T. \& Lempicki, R. A. Bioinformatics enrichment tools: paths toward the comprehensive functional analysis of large gene lists. Nucleic Acids Res. 37, 1-13 (2009).

42. Raudvere, U. et al. g:Profiler: a web server for functional enrichment analysis and conversions of gene lists (2019 update). Nucleic Acids Res. 47, W191-W198 (2019).

43. Eden, E., Navon, R., Steinfeld, I., Lipson, D. \& Yakhini, Z. GOrilla: a tool for discovery and visualization of enriched GO terms in ranked gene lists. BMC Bioinformatics 10, 48 (2009).

44. Eden, E., Lipson, D., Yogev, S. \& Yakhini, Z. Discovering motifs in ranked lists of DNA sequences. PLoS Comput. Biol. 3, e39 (2007).

45. Metsalu, T. \& Vilo, J. ClustVis: a web tool for visualizing clustering of multivariate data using Principal Component Analysis and heatmap. Nucleic Acids Res. 43, W566-570 (2015).

46. Zhou, Y. et al. Metascape provides a biologist-oriented resource for the analysis of systems-level datasets. Nat. Commun. 10, 1523 (2019).

47. Stickel, S., Gomes, N. \& Su, T. T. The role of translational regulation in survival after radiation damage; an opportunity for proteomics analysis. Proteomes. 2, 272-290 (2014).

48. Dang, X. et al. HIPK2 overexpression relieves hypoxia/reoxygenation-induced apoptosis and oxidative damage of cardiomyocytes through enhancement of the Nrf2/ARE signaling pathway. Chem. Biol. Interact. 316, 108922 (2020).

49. Farhood, B. et al. Targeting of cellular redox metabolism for mitigation of radiation injury. Life Sci. 250, 117570 (2020).

50. Weinstein, N., Mendoza, L. \& Alvarez-Buylla, E. R. A computational model of the endothelial to mesenchymal transition. Front. Genet. 11, 40 (2020).

51. Bertoli, C., Skotheim, J. M. \& de Bruin, R. A. Control of cell cycle transcription during G1 and S phases. Nat. Rev. Mol. Cell Biol. 14, 518-528 (2013).

52. Chwieralski, C. E., Welte, T. \& Buhling, F. Cathepsin-regulated apoptosis. Apoptosis 11, 143-149 (2006).

53. Jelonek, K., Pietrowska, M. \& Widlak, P. Systemic effects of ionizing radiation at the proteome and metabolome levels in the blood of cancer patients treated with radiotherapy: the influence of inflammation and radiation toxicity. Int. J. Radiat. Biol. 93, 683-696 (2017).

54. Muller, M. Cellular senescence: molecular mechanisms, in vivo significance, and redox considerations. Antioxid. Redox. Signal. 11, 59-98 (2009).

55. Wu, X., Zheng, W., Jin, P., Hu, J. \& Zhou, Q. Role of IGFBP1 in the senescence of vascular endothelial cells and severity of agingrelated coronary atherosclerosis. Int. J. Mol. Med. 44, 1921-1931 (2019).

56. Baege, A. C., Disbrow, G. L. \& Schlegel, R. IGFBP-3, a marker of cellular senescence, is overexpressed in human papillomavirusimmortalized cervical cells and enhances IGF-1-induced mitogenesis. J. Virol. 78, 5720-5727 (2004).

57. Hong, S. \& Kim, M. M. IGFBP-3 plays an important role in senescence as an aging marker. Environ. Toxicol. Pharmacol. 59, 138-145 (2018).

58. Severino, V. et al. Insulin-like growth factor binding proteins 4 and 7 released by senescent cells promote premature senescence in mesenchymal stem cells. Cell Death Dis. 4, e911 (2013).

59. Wang, W. et al. Integrin beta3 Mediates the Endothelial-to-Mesenchymal Transition via the Notch Pathway. Cell Physiol. Biochem. 49, 985 (2018).

60. Evrard, S. M. et al. Endothelial to mesenchymal transition is common in atherosclerotic lesions and is associated with plaque instability. Nat. Commun. 7, 11853 (2016).

61. Choi, S. H. et al. Tumour-vasculature development via endothelial-to-mesenchymal transition after radiotherapy controls CD44v6(+) cancer cell and macrophage polarization. Nat. Commun. 9, 5108 (2018).

62. Xiao, L. et al. Tumor endothelial cells with distinct patterns of TGFbeta-driven endothelial-to-mesenchymal transition. Cancer Res. 75, 1244-1254 (2015).

63. Yao, H. et al. Inhibitory effect of bone morphogenetic protein 4 in retinal pigment epithelial-mesenchymal transition. Sci. Rep. 6, 32182 (2016).

64. Xian, S. et al. Activation of activin/Smad2 and 3 signaling pathway and the potential involvement of endothelial-mesenchymal transition in the valvular damage due to rheumatic heart disease. Mol. Med. Rep. 23, 1 (2021). 
65. Yao, Y., Yao, J. \& Bostrom, K. I. SOX Transcription factors in endothelial differentiation and endothelial-mesenchymal transitions. Front Cardiovasc. Med. 6, 30 (2019).

66. Hariono, M. et al. Arylamide as potential selective inhibitor for matrix metalloproteinase 9 (MMP9): design, synthesis, biological evaluation, and molecular modeling. J. Chem. Inf. Model. 60, 349-359 (2020).

67. Klein, T. \& Bischoff, R. Physiology and pathophysiology of matrix metalloproteases. Amino Acids 41, 271-290 (2011).

68. Vermeulen, K., Van Bockstaele, D. R. \& Berneman, Z. N. The cell cycle: a review of regulation, deregulation and therapeutic targets in cancer. Cell Prolif. 36, 131-149 (2003).

69. Chatterjee, N. \& Walker, G. C. Mechanisms of DNA damage, repair, and mutagenesis. Environ. Mol. Mutagen. 58, 235-263 (2017).

70. Tamulevicius, P., Wang, M. \& Iliakis, G. Homology-directed repair is required for the development of radioresistance during S phase: interplay between double-strand break repair and checkpoint response. Radiat. Res. 167, 1-11 (2007).

71. Elmore, S. Apoptosis: a review of programmed cell death. Toxicol. Pathol. 35, 495-516 (2007).

72. Kiraz, Y., Adan, A., Kartal Yandim, M. \& Baran, Y. Major apoptotic mechanisms and genes involved in apoptosis. Tumour Biol. 37, 8471-8486 (2016).

73. Guicciardi, M. E. \& Gores, G. J. Life and death by death receptors. FASEB J. 23, 1625-1637 (2009).

74. Santucci, R., Sinibaldi, F., Cozza, P., Polticelli, F. \& Fiorucci, L. Cytochrome $c$ : an extreme multifunctional protein with a key role in cell fate. Int. J. Biol. Macromol. 136, 1237-1246 (2019).

75. Kirkland, J. L. \& Tchkonia, T. Cellular senescence: a translational perspective. EBioMedicine 21, 21-28 (2017).

76. Calcinotto, A. et al. Cellular senescence: aging, cancer, and injury. Physiol. Rev. 99, 1047-1078 (2019).

77. He, Y. et al. Cellular senescence and radiation-induced pulmonary fibrosis. Transl. Res. 209, 14-21 (2019).

78. Tchkonia, T., Zhu, Y., van Deursen, J., Campisi, J. \& Kirkland, J. L. Cellular senescence and the senescent secretory phenotype: therapeutic opportunities. J. Clin. Invest. 123, 966-972 (2013).

79. Sanchez-Duffhues, G., Garcia de Vinuesa, A. \& Ten Dijke, P. Endothelial-to-mesenchymal transition in cardiovascular diseases: developmental signaling pathways gone awry. Dev. Dyn. 247, 492-508 (2018).

80. Clere, N., Renault, S. \& Corre, I. Endothelial-to-mesenchymal transition in cancer. Front. Cell Dev. Biol. 8, 747 (2020).

81. Almalki, S. G. \& Agrawal, D. K. Effects of matrix metalloproteinases on the fate of mesenchymal stem cells. Stem Cell Res. Ther. 7, 129 (2016).

\section{Acknowledgements}

We would like to thank Mr. Michael Woolbert, USUHS, Bethesda MD, USA, for assistance with the RS2000 X-ray irradiator, and the University of Wisconsin Medical Radiation Research Center, Madison, WI, USA, for assisting with TLD calibration for dosimetry. We would like to thank Grace V. Brehm for performing experiments and data analysis related to revisions for this manuscript. This work was supported by a pilot grant from the Opportunity Funds Management Core of the Centers for Medical Countermeasures against Radiation, National Institutes of Health (NIH), National Institutes of Allergy and Infectious Diseases, grant number U19AI067773 (Award Number 5U19AI067773-14, P.I. Regina M. Day), and by Award Number DM178018 (P.I. Regina M. Day) from the Defense Medical Research and Materiel Command, Radiation Health Effects Research Program, Joint Program Committee 7. Some of the authors are employees of the U.S. Government, and this work was prepared as part of their official duties. Title 17 U.S.C. $\$ 105$ provides that 'Copyright protection under this title is not available for any work of the United States Government.' Title 17 U.S.C \$101 defines a U.S. Government work as a work prepared by a military service member or employees of the U.S. Government as part of that person's official duties. The views in this article are those of the authors and do not necessarily reflect the views, official policy, or position of the National Institute of Allergy and Infectious Diseases or the National Institutes of Health, the Uniformed Services University of the Health Sciences, the Armed Forces Radiobiology Research Institute, Department of the Navy, Department of Defense or the U.S. Federal Government.

\section{Author contributions}

RMD designed the project; RMB, CLD, ARS, JES, and RMD performed experiments and collected data; RMB, CLD, ARS, JES, and RMD performed data analysis; RMB and RMD wrote the manuscript. All authors read and reviewed the full manuscript.

\section{Competing interests}

The authors declare no competing interests.

\section{Additional information}

Supplementary Information The online version contains supplementary material available at https://doi.org/ 10.1038/s41598-021-03636-7.

Correspondence and requests for materials should be addressed to R.M.D.

Reprints and permissions information is available at www.nature.com/reprints.

Publisher's note Springer Nature remains neutral with regard to jurisdictional claims in published maps and institutional affiliations.

Open Access This article is licensed under a Creative Commons Attribution 4.0 International License, which permits use, sharing, adaptation, distribution and reproduction in any medium or
format, as long as you give appropriate credit to the original author(s) and the source, provide a link to the Creative Commons licence, and indicate if changes were made. The images or other third party material in this article are included in the article's Creative Commons licence, unless indicated otherwise in a credit line to the material. If material is not included in the article's Creative Commons licence and your intended use is not permitted by statutory regulation or exceeds the permitted use, you will need to obtain permission directly from the copyright holder. To view a copy of this licence, visit http://creativecommons.org/licenses/by/4.0/.

This is a U.S. Government work and not under copyright protection in the US; foreign copyright protection may apply 2021 